\title{
La política monetaria y el crecimiento económico en Colombia, 1990-2010*
}

\section{Monetary policy and economic growth in Colombia, 1990-2010}

\author{
María Esperanza Cuenca Coral** \\ Felipe Amaya*** \\ Bryan Andrés Castrillón*****
}

Recibido: 27 de noviembre de 2014

Revisado: 14 de enero de 2015

Aprobado: 16 de marzo de 2015

\section{Resumen}

Se buscó identificar y analizar las dinámicas de la política monetaria colombiana en relación con el crecimiento económico presentado y, a la vez, establecer las fortalezas y debilidades frente a las coyunturas presentadas en el país. El aporte del análisis realizado radica en su nivel de desagregación y en la aplicación de la metodología que pretende

* Como Citar este articulo: Cuenca, M; Amaya, F.\& Castrillón, B. (2014). La política monetaria y el crecimiento económico en Colombia 1990-2010. Revista CIFE, 16(25). 71-121.

** Maestría en economía pontificia universidad Javeriana, Docente tiempo completo Universidad de América, correo: mecuenca@gmail.com

*** Economista Universidad de América. Consultor DANE correo: sergiofelipe8@hotmail.com

****Economista - Universidad de América. Fundación Panamericana para el Desarrollo FUPAD Correo: bryhamon@ hotmail.com 
establecer la regla de Taylor utilizando el crecimiento económico y las variaciones del IPC, la cual es de reciente incorporación al análisis monetario nacional que busca conocer los orígenes de problemas monetarios. Hecha la caracterización del crecimiento económico y la política económica, la estimación teórica se desarrolló con cifras computadas por las instituciones del país, asegurando su veracidad y pertinencia.

Palabras clave: política monetaria, regla de Taylor, tasa de interés, tasa de cambio, inflación.

Clasificación JEL: E5, E51, F31, E31, E43, E13

\section{Abstract}

This paper pretends to analyze the dynamics of the Colombian monetary policy on economic growth and simultaneously presented to establish the strengths and weaknesses compared to the joints presented in the country. The contribution of the analysis lies in its level of disaggregation and the application of the methodology that aims to establish the Taylor rule using economic growth and changes in the CPI, which is of recent transposition monetary analysis that seeks to understand the origins of monetary problems. Build the characterization of economic growth and economic policy, the theoretical estimate was developed with data published by the institutions of the country, ensuring their accuracy and relevance.

Keywords: Monetary Policy, Taylors rule, Interest Rate, Exchange Rate,Inflation.

Classification JEL: E5, E51, F31, E31, E43, E13 


\section{Introducción}

La política monetaria es un instrumento de la política económica por medio del cual se puede incrementar la tasa de empleo, garantizar estabilidad de precios e incentivar el crecimiento económico. Cada uno de los países genera las condiciones para la ejecución idónea de las políticas diseñadas con el bien de ajustar el equilibrio macroeconómico. Ahora bien, hay una pregunta que ha surgido acerca del carácter endógeno de la política monetaria, la cual es universal, y se ha evaluado en otros trabajos a lo largo de los bancos centrales.

Este artículo tiene como objetivo identificar y analizar las dinámicas de la política monetaria colombiana en relación con el crecimiento económico presentado y, a la vez, establecer las fortalezas y debilidades frente a las coyunturas presentadas en el país. El aporte del análisis realizado radica en su nivel de desagregación y en la aplicación de la metodología que pretende establecer la regla de Taylor utilizando el crecimiento económico y las variaciones del IPG, el cual es de reciente incorporación al análisis monetario nacional que busca conocer los orígenes de problemas monetarios. Hecha la caracterización del crecimiento económico y la política económica, la estimación teórica se desarrolló con cifras computadas por las instituciones del país, asegurando su veracidad y pertinencia.

Son varios los trabajos realizados en el mundo que tratan de calibrar la regla de Taylor. Por ejemplo, el Banco Central Europeo (2008) realizó un modelo para relacionar la tasa de interés y la regla de Taylor. Se evidencia recientemente el interés por el tema, por medio de los trabajos realizados por diferentes autores, entre los que se cuentan Carlos J. Rodríguez Fuentes, David Padrón Marrero, Ignacio Perrotini, Gloria Bernal, Johanna Táutiva, Andrés Felipe Giraldo Palomino, entre otros. Para la República Dominicana se ha evaluado la misma regla Taylor, pero ampliada mediante un CVAR, es decir, un vector autorregresivo cointegrado.

En el trabajo de Rodríguez Fuentes, Padrón Marrero y Olivera Herrera (p. 235), los autores afirman que, "en la mayoría de los libros de macroeconomía, al considerar que las autoridades monetarias pueden ejercer un control estricto sobre la cantidad de dinero en circulación, se suele representar la oferta monetaria como una función recta vertical con respecto al tipo de interés. Y en este contexto, las intervenciones de política monetaria por parte del banco central se grafican como desplazamientos horizontales de la mencionada función".

En Colombia, el Banco de la República precisa como objetivo primario de la política monetaria alcanzar y mantener una tasa de inflación baja y estable, así como también lograr que el producto crezca alrededor de su tendencia a largo plazo. El cumplimiento de este objetivo se constituye en la base primordial para un crecimiento sostenido de la 
economía que supone, además, genere empleo y mejore el nivel de vida de la población (Sánchez, Fernández y Armenta (2005, p. 11). El presente trabajo busca establecer dos aspectos importantes: si la política monetaria es o no endógena, con el fin de establecer el modelo para caracterizar su comportamiento; en segunda instancia, si es una política endógena, estimar la regla de Taylor.

Con la Constitución de 1991 se estableció en Colombia que el objetivo principal de la política del Banco de la República es la preservación de la estabilidad de los precios: "Artículo 373. El Estado, por intermedio del Banco de la República, velará por el mantenimiento de la capacidad adquisitiva de la moneda" . Para lograr tal cometido, la Constitución además dota de un importante grado de autonomía al Banco de la República. De igual manera establece que "Las operaciones de financiamiento a favor del Estado requerirán la aprobación unánime de la Junta Directiva, a menos que se trate de operaciones de mercado abierto"2, con lo cual se elimina el señoreaje, que había sido hasta entonces importante fuente de financiación del gasto público.

En un análisis como el propuesto, son varios los métodos que pueden aparecer como útiles en su desarrollo. El primero de ellos es partir de un modelo de mínimos cuadrados ordinarios, el cual se realizó durante la investigación, y que dio algunos resultados inapropiados y poco sorprendentes. Es por ello que, siguiendo algunos de los modelos consultados e inclusive el artículo seminal de Sims (2006), se propone intentar un vector autorregresivo, el cual aporta las conclusiones del presente estudio. Se realizaron las pruebas necesarias, cuyos resultados se presentarán a continuación.

El documento se divide en varias partes: antecedentes, referentes teóricos y conceptuales y el caso colombiano. En este último se muestran los aspectos más importantes, como las crisis del periodo de estudio. Al finalizar, se exponen el modelo econométrico y sus resultados.

\section{Antecedentes}

De las revisiones establecidas en la investigación, "se ha podido establecer que la política monetaria en Colombia ha estado determinada por el contexto internacional y la doctrina económica - o pensamiento económico- que lidere el mundo en un momento determinado" (Sánchez, Fernández y Armenta, 2005, p. 10). En el año de 1881 se creó en Colombia el Banco Nacional, bajo el gobierno de Rafael Núñez, cuando los bancos comerciales de la época fueron obligados a aceptar los billetes emitidos con base en su valor nominal. Estas políticas desarrolladas por el presidente Núñez dieron origen a la

1 Constitución Política de Colombia de 1991. Título XII. Del régimen económico y de la Hacienda Pública. Capítulo 6. De la Banca Central.

2 ibíd. 
primera implementación de una política monetaria definida. Ejemplo de esto fue la puesta en funcionamiento del curso forzoso de la moneda en la economía colombiana.

Posteriormente, en el gobierno del presidente Pedro Nel Ospina - cuyo mandato rigió de1922 a 1926-, y en cumplimiento de la Ley 60 de 1922, se autorizó la creación de un banco central. "Es importante y necesario aclarar que el papel del Banco de la Republica estuvo limitado entre 1923 y 1931, dado que solo debía mantener la convertibilidad del papel moneda al oro" (Sánchez, Fernández y Armenta, 2005, p. 10). En materia fiscal, desde la creación del banco hasta la creación de la Constitución de 1991, la emisión de dinero se constituyó en fuente de financiamiento del Gobierno nacional. "Este uso se dio frecuentemente y aumentó desde la crisis de 1923 y en la crisis de los años ochenta" Gandour Pordominsky (2008). Dicha financiación se dio en tres modalidades. La primera se otorgaba bajo préstamos directos del gobierno, previa suscripción de un contrato de empréstito. Con esta modalidad se buscó limitar la adquisición de los créditos por medio de montos establecidos y aprobados por la junta monetaria ${ }^{3}$. La segunda modalidad consistía en la compra, por parte del banco, de los bonos de deuda pública, bonos emitidos por el Gobierno nacional; esta modalidad se tuvo en cuenta desde la creación del banco y fue utilizada con mayor frecuencia por el gobierno entre las décadas de los treinta y los cincuenta ${ }^{4}$. La tercera modalidad de financiación era el traslado de las utilidades generadas por la comercialización de divisas efectuadas por el banco a la cuenta especial de cambios". "Esa cuenta que llevaba el Banco de la República era un registro contable de las operaciones activas y pasivas que arrojaban las operaciones de compra y venta de oro y divisas que realizaba la entidad. Cuando al final de mes estas operaciones reportaban un resultado positivo, el respectivo crédito era entregado al Gobierno y contabilizado como un ingreso corriente" (Alviar y Rojas, 1985, p. 512, citado en Gandour Pordominsky, 2008) $)^{6}$.

3 Las normas que entre 1923 y 1990 ampliaron el cupo de crédito del Gobierno ante el Banco de la República fueron, entre otras, la Ley 73 de 1930, el Decreto Ley 1361 de 1942, el Decreto Ley 3882 de 1949, el Decreto 756 de 1950 y la Ley 34 de 1984.

4 Uno de los casos en los que el Banco de la República adquirió títulos de deuda del Gobierno fue la Ley 73 de 1930. Como la misma norma autorizaba al Banco a comprar dichos títulos a entidades oficiales y en el mercado, se abrió la posibilidad de que el Banco adquiriera de modo indirecto títulos de deuda del Gobierno (Ibáñez Najar, 1990, p. 344). Finalmente, en 1955, como apoyo a la siderúrgica Paz del Río y para permitir su ampliación, el Gobierno emitió bonos de deuda cuyo principal comprador fue el Banco de la República (López Mejía, 1990b, p. 481).

5 Como señala Montenegro (1983, p. 104), “(las) entregas al Gobierno de las UCVD [utilidades por compra venta de divisas] constituyen expansión monetaria de carácter primario. Su naturaleza es idéntica a la de un crédito cualquiera al Gobierno central. La razón de este hecho es muy simple. Por su propia naturaleza, cualquier transferencia de carácter monetario del banco central a cualquier agente de la economía implica expansión primaria de circulante. Las ganancias de capital por el manejo de reservas y, por consiguiente, las UCVD son un excedente de carácter contable que pertenece usualmente a los bancos centrales y cuya monetización es discrecional".

6 La Cuenta Especial de Cambios fue creada por el Banco el 31 de octubre de 1934, aprobada por la Ley 7 de 1935 , con el propósito de que las utilidades obtenidas por la compra y venta de oro físico y por giros sobre el exterior sirvieran para el pago de los créditos otorgados al Gobierno por el emisor entre 1933 y 1934. 
A finales de los años ochenta, y con la aparición del Consenso de Washington, las medidas de política monetaria se reorientaron para favorecer la eficiencia del mercado en la asignación de recursos. El sustento teórico de este Consenso se basó en las políticas de libre mercado y en la promoción de la no intervención del Estado en las economías del mundo. Como explican Sánchez, Fernandez y Armenta (2005, p. 22), “(...) Antes de los noventa la política monetaria se daba en un marco de esquemas híbridos entre política monetaria y cambiaria, con alto grado de discrecionalidad y sin movilidad de capitales. Solo hasta después de los noventa se dio gradualmente una flexibilización".

En el país también se consideró la nueva reglamentación respecto a la política monetaria. Para 1991 se dio el proceso de apertura económica, con el cual se estableció la libre movilidad de capitales, se suprimió el control de cambios, y la posesión y negociación de divisas dejó de ser exclusividad del Banco de la República, donde dichas operaciones podrían hacerse entonces por medio de intermediarios del mercado cambiario. En cuanto a la inversión extranjera, en el Acuerdo de Cartagena de 1987 se eliminó la lista de prohibiciones y restricciones a la inversión. Sin embargo, la movilidad de capital no se abrió completamente, se aplicó un depósito de endeudamiento externo, donde los prestamos permanecerían durante un periodo determinado en el Banco de la Republica, con el fin de evitar el arbitraje internacional de interés. Además, con los propósitos de dar autonomía a la política monetaria, la estructura de plazos de endeudamiento externo se modificó para contribuir a la solidez del país, evitar salidas imprevistas de capital y disminuir el endeudamiento externo.

En la figura 1 se observa que la evaluación del dinero en la economía colombiana estuvo ligada íntimamente al tipo cambiario presente en la época. En los años siguientes, las metas multianuales fueron de rango tanto a uno como a dos años. El Banco de la República contaba con metas de inflación a corto plazo. Además de estas estableció una meta de inflación a largo plazo que en un principio fue puntual, de $3 \%$, y de rango de 2 a $4 \%$. Esta situación de metas se reforzó con la estrategia de comunicación por parte del Banco de la República, que estuvo compuesta por comunicados de prensa, informes al Congreso, informes de inflación y presentaciones de la junta directiva del Banco. Esta se complementó con los compromisos legales del Banco. "Por ejemplo, dos veces en el año la junta directiva debe entregar un informe al Congreso de la República, y cada cuatro veces al año hace disponibles informes de inflación al público en general” (Sánchez, Fernández y Armenta, 2005, p. 5).

Este nuevo contexto exigía tener en cuenta que, dentro de la elaboración de las políticas por parte de la autoridad, una de las preguntas es la eficacia de la política monetaria respecto a poder estimular el nivel de actividad económica. Gómez (2006, p. 45) afirma que se ha demostrado y que es conocido que la política monetaria tiene impacto en la actividad económica a corto plazo, pero que no tiene efecto alguno a largo plazo. Un ejemplo de esto es que, como resultado de la estanflación de Estados Unidos en los años 
setenta, las expectativas racionales demostraron que la expansión monetaria se incorpora en las expectativas de inflación, y el efecto de una política monetaria expansiva es solamente sobre la inflación y a largo plazo. En este periodo la política monetaria no tiene efecto.

Figura 1. Crecimiento anual del dinero en Colombia durante el siglo XX. Base monetaria y medios de pago 1905-2000

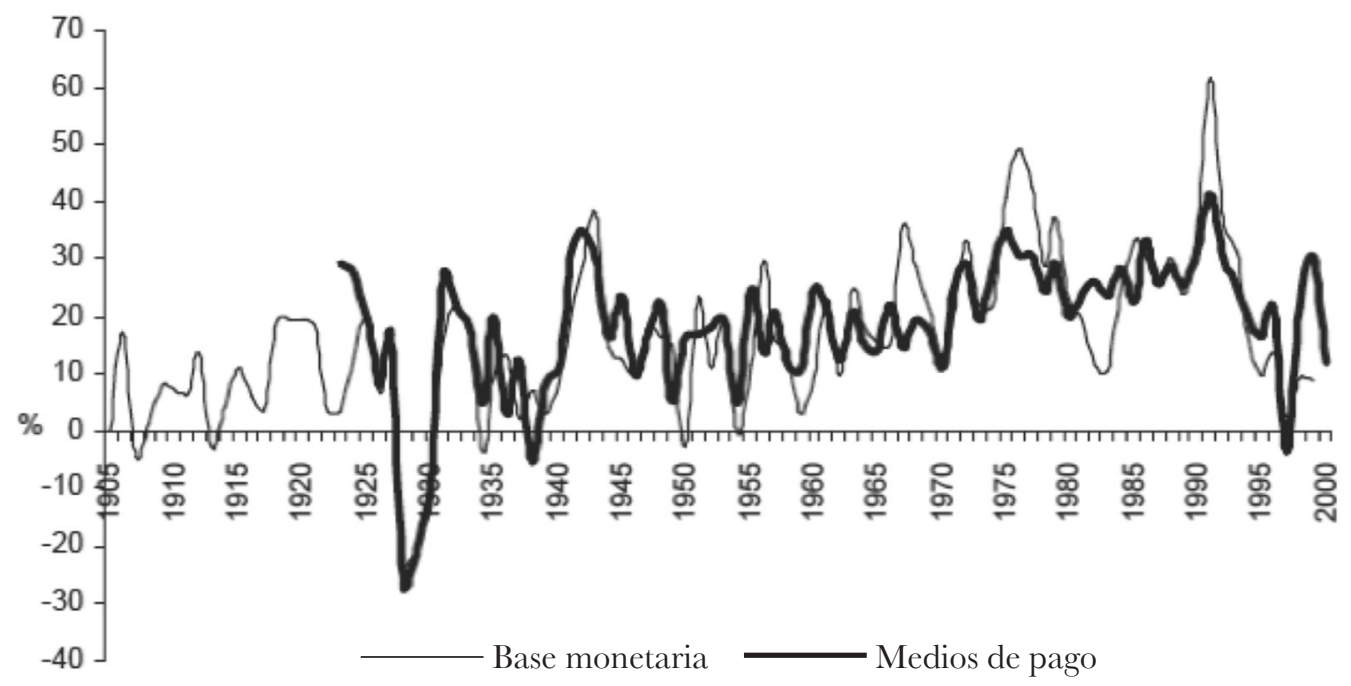

Fuente: Sánchez, Fernández y Armenta (2005).

En el caso colombiano, y de acuerdo con Clavijo (2000):

desde 1996 es un proceso de desinflación que se ha amparado en una preocupante desaceleración del crecimiento económico de largo plazo, debido a serios problemas estructurales en las finanzas públicas, en el frente del orden público y en contradicciones en el manejo de los instrumentos cambiarios respecto de los monetarios. Más aun, esta falta de austeridad fiscal y de coherencia en el manejo del sistema cambiario respecto de la política monetaria a lo largo de toda esta década ha hecho que la estrategia de desinflación haya tenido baja credibilidad tanto interna como externa, tal como lo concluyera el propio equipo técnico del Banco de la República en un estudio reciente sobre estrategia antiinflacionaria (Uribe et. al., 1999 p. 13). Dicho de otra manera, Colombia ha experimentado una "desinflación fortuita" durante los años 1998-99, entendiendo como tal la resultante del debilitamiento del sector productivo, del incremento del desempleo, del estallido de la "burbuja especulativa" de los bienes raíces que se fue inflando durante los años 1993-97. Todo ello ha traído graves consecuencias para el sector financiero, afectando estructuralmente su capacidad crediticia. 
Por ellos, y como sugiere Clavijo (2000 p. 36), "se sustenta la necesidad de implementar un esquema de inflación objetivo" . Es significativo mencionar en esta investigación que, dado el problema de fuga de capital y lavado de activos en el país, se debía disciplinar la política monetaria colombiana, esto a razón de la dinámica de la movilidad de capital. Por un lado, la estabilidad monetaria no garantizaba la posibilidad de control de la estabilidad nominal por la irregular demanda de dinero, y, por otro lado, la estrategia de inflación objetivo ya tenía aceptación internacional, incluso por el FMI. Con los acuerdos suscritos con el FMI se establecieron metas de inflación multianuales.

El banco central colombiano comenzó a definir la franja de tasa de interés de intervención con base en la diferencia entre la meta y el pronóstico de inflación. En 2001, el criterio de desempeño se basó en las metas de inflación trimestrales, y se estableció una línea de referencia en remplazo del corredor monetario. Con el primer acuerdo con el FMI se definieron metas de inflación de $10 \%, 8 \%$ y $6 \%$ para 2000, 2001 y 2002, respectivamente. Esas metas fueron cumplidas rigurosamente por la política de aumento de las tasas de interés para defender la banda cambiaria en años anteriores, y de esta manera se introdujeron los elementos característicos del régimen de inflación objetivo.

\section{Referentes teóricos y conceptuales de la investigación}

La teoría monetaria puede considerarse desde el siglo XVI, asociada a su concepción más elemental, según la cual se tenía claro que la subida del nivel general de precios se da con un incremento de la oferta de dinero. El precursor es el monje español Martín de Azpilicueta, quien señaló que el dinero vale más cuando es más escaso que cuando es abundante. Este planteamiento fue desarrollado por otros autores de su época tras la llegada de metales preciosos provenientes de América y las inflaciones originadas como consecuencia de dicha abundancia.

Para Shumpeter (1934), el primer precedente claro se encuentra en la obra de Bernardo Davanzati en 1588. No fue sino hasta mediados del siglo XVIII que se empezó a hablar de velocidad de circulación del dinero, circunstancia que se atribuye habitualmente a Richard Cantillon, quien destacó que un aumento de tal velocidad tiene los mismos efectos que un incremento del stock monetario, mientras que su reducción contribuye a frenar el alza de los precios. Dicha teoría se convirtió en este amplio periodo de tiempo y hasta ya entrado el siglo XX, en la teoría monetaria ortodoxa aceptada por algunos de los economistas clásicos y luego por los neoclásicos. Los últimos precisamente se encargaron

7 Svensson (2005) agrupa estas características en tres: (a) meta de inflación, (b) transparencia y (c) una operatividad del banco central hacia el futuro. Siendo así, es importante describir que el objetivo de inflación es un mandato constitucional que requiere que el banco central - para el caso de Colombia, el Banco de la República- persiga la estabilidad de precios y que, en ausencia de un requerimiento legal o constitucional, el objetivo de la estabilidad de los precios pueda ser parte de la manera de pensar y de tomar decisiones de los encargados de ejecutar la política, como es afirmado por Gómez (2006). Además, Svensson (2005) definió la transparencia como la claridad en la racionalidad de las decisiones de política monetaria y la disposición de acceso que permita conocer la racionalidad de esas decisiones. 
de complementar, sistematizar y representar en forma matemática dichas ideas, sobre todo el norteamericano Irving Fisher y los representantes de la escuela de Cambridge en Europa, Pigou, Robertson e incluso el propio Keynes. "Fisher desarrolló una ecuación de cambio de la teoría cuantitativa del dinero, precisando una relación entre las variables y aportando a los principios de la econometría" (Fernández, Rodríguez, Parejo, Bernardino y Galindo, 2003, p. 58). La fórmula relaciona la oferta monetaria y su velocidad de circulación con el nivel de precios y da un carácter determinante a la oferta.

El enfoque de saldos de caja fue una de las primeras críticas a la versión del enfoque transaccional de la teoría cuantitativa. En efecto, surgió principalmente entre un grupo de economistas de Cambridge durante la Primera Guerra Mundial. Marshall y Pigou fueron los principales exponentes de la nueva corriente, cuyo interés se centró en analizar los factores que determinan la demanda de dinero por parte del público. Para estos economistas, el dinero no es exclusivamente un medio de cambio, como señalaba el enfoque anterior, sino activo financiero que las personas desean conservar en forma de saldo de caja. El enfoque de saldos reales se atribuye a Don Patinkin, quien constituye una de las últimas versiones de la teoría cuantitativa de dinero aparecida en 1952, en la cual este autor trató de explicar en mayor detalle el proceso por el cual un incremento de la cantidad de dinero se traduce en inflación. A este proceso se le denomina efecto Patinkin del saldo real, en clara contraposición al efecto de saldos de caja de la escuela de Cambridge. Para los cuantitativitas tradicionales, el incremento de la cantidad nominal de dinero encerraba efecto riqueza, que producía un aumento del gasto y de la demanda, que al existir pleno empleo se traducía en una elevación del nivel general de los precios.

$$
\Delta M \longrightarrow \Delta W_{\mathrm{m}} \longrightarrow \Delta \text { Gasto } \equiv \Delta D \longrightarrow \Delta P
$$

El planteamiento de Patinkin trata de que, si se produce ese incremento en el stock nominal de dinero, lo primero que sucede es que su stock real aumenta, pues todavía los precios permanecen constantes, lo que provoca una variación respecto a la relación deseada por el público entre su liquidez real y su renta real, con lo que incrementa la demanda para eliminar ese exceso y se elevan los precios (Fernández, Rodríguez, Parejo, Bernardino y Galindo, 2003, p. 60).

Por otro lado, la regla de Taylor fue formulada por John B. Taylor en 1993, y para Estados Unidos se reveló que la conducción de la política monetaria por parte de la Reserva Federal de los Estados Unidos se podía simplificar en una regla para la tasa de interés de fondos federales en la que esta tasa respondiera positivamente a choques inflacionarios y a choques sobre el producto (Fernández, Rodríguez, Parejo, Bernardino y Galindo, 2003, p. 2). Taylor denotó la regla de política monetaria de la siguiente forma: 
ISSN: 0124-3551 / Año 16, No 25 / julio-diciembre / pp. 71-122

$$
r=p+0,5 y+0,5(p-2)+2
$$

En la ecuación, $r$ es la tasa de interés de los fondos federales, $p$ es la tasa de inflación de los últimos cuatro trimestres, en tanto y es la desviación del nivel de producto con respecto a una meta de producto real. A partir de esta regla se predice que la tasa de interés $r$ debe aumentar si la inflación se encuentra por encima de una meta de $2 \%$ o si el producto real se desvía de su tendencia ${ }^{8}$. Partiendo del planteamiento de Taylor y de la formulación de la regla de política, el principio de Taylor se define como la búsqueda, por parte del banco central, de perturbar significativamente la tasa de interés real con el fin de acercar la inflación a su meta. En 2000, en el documento "Estabilización y política monetaria: la experiencia internacional", Taylor argumentó que

el uso de reglas de política monetaria en economías de mercado emergentes posee muchas de las ventajas que han sido encontradas en investigaciones y en la práctica, relativas a economías desarrolladas. Para aquellas economías emergentes que no han optado por una política de fijación 'permanente' del tipo de cambio, (...) la única opción de política monetaria firme sería la basada en la trinidad de un tipo de cambio flexible, una meta de inflación y una regla de política monetaria. Sin embargo, las condiciones de mercado en las economías emergentes pueden requerir modificaciones a la regla de política típica recomendada para economías con mercados financieros más desarrollados. (Taylor, 2009, p. 19).

En el ámbito internacional, son varios los trabajos que tratan de calibrar la regla de Taylor. Por ejemplo, el Banco Central Europeo (2008) realizó un modelo para relacionar la tasa de interés y la regla de Taylor. En este documento, los resultados conducen a un modelo ARIMA. La aplicación de la regla de Taylor se evidencia recientemente en los trabajos realizados por diferentes autores, por ejemplo, Carlos J. Rodríguez Fuentes, David Padrón Marrero, Ignacio Perrotini, Gloria Bernal, Johanna Táutiva, Andrés Felipe Giraldo Palomino, entre otros. Para la República Dominicana se ha evaluado la misma regla Taylor, ampliada por medio de un CVAR, es decir, un vector autorregresivo cointegrado.

En La endogeneidad de la oferta monetaria. Teoría y evidencia empirica para la economía española, Rodríguez Fuentes, Padrón Marrero y Olivera Herrera (p. 15) afirman que, "en la mayoría de los libros de macroeconomía, al considerar que las autoridades monetarias pueden ejercer un control estricto sobre la cantidad de dinero en circulación, se suele representar la oferta monetaria como una función recta vertical con respecto al tipo de interés. Y en este contexto, las intervenciones de política monetaria por parte del banco central se grafican como desplazamientos horizontales de la mencionada función".

$\mathrm{Al}$ entender así esta función, suele decirse que la oferta monetaria es exógena, en la medida en que viene dada por las intervenciones discrecionales del banco central en

8 Taylor, J. B. (1965). The Portable Veblen. New York: Lerner Max Ed. Citado en Kalmanovitz, S. (2003). La politica monetaria. Bogotá: Publicaciones Banco de la República, p. 5. 
los mercados primarios de dinero. Ahora bien, no puede interpretarse esta afirmación como una más coloquial y no menos común: pensar que los bancos centrales no toman en consideración variables económicas para la determinación de los agregados monetarios.

Este es el razonamiento que durante años se ha empleado para explicar los movimientos de la curva LM en el contexto del Modelo IS-LM, que incluye las ideas de Keynes en su Teoría general (Keynes, 1973a). Dada la ambigüedad de las ideas keynesianas, se presenta un interesante debate, pero son muchos los autores que no comparten esta opinión (Fernández, Rodríguez, Parejo, Bernardino y Galindo, 2003, p. 87). En la Teoría general de la ocupación, el interés y el dinero, Keynes asumió la existencia de tres variables independientes en su análisis, siendo una de ellas el tipo de interés; esto puede ser interpretado como la intención de Keynes de asumir la existencia de una oferta monetaria exógena. Otros autores defienden la idea de que Keynes considera - en los desarrollos de su Teoría general- que tales variables eran conocidas de antemano (véase, por ejemplo, Dow, 1997), pero no exógenas al sistema económico. Ahora bien, esto ya se veía en obras precedentes, como el Treatise on Money (Keynes, 1971), obra en la que Keynes reconoció el importante papel que desempeñaba el sistema bancario en la oferta monetaria, sin dejar de lado al banco central.

En el trabajo desarrollado por Rodríguez Fuentes, Padrón Marrero y Olivera Herrera en 2004, estos autores analizaron la relación de causalidad entre los agregados monetarios en España con el propósito de establecer el carácter de la oferta monetaria (exógeno o endógeno). En él se estudió la causalidad de estadísticas entre los activos de caja y los agregados monetarios. Los autores aclaran que el propósito de este trabajo no es profundizar en esta controvertida cuestión, por interesante que sea, sino más bien, analizar el significado de la existencia de una oferta monetaria endógena. Es importante aclarar que los autores definen y conceptualizan que cuando se afirma que la oferta de dinero es una variable exógena, se entiende como que la autoridad monetaria fija la política monetaria considerando variables, pero no se toma en cuenta el resultado del momento económico, es decir, se considera exógena si, para determinar la tasa de intervención, no se incorporan parámetros de la economía.

En las conclusiones obtenidas en trabajos anteriores referidos al caso español, por ejemplo, en documentos como el de Camarero (1993) y Palacio-Vera (2001) se establece la existencia de una causalidad contraria a la esperada en el Modelo del Multiplicador Monetario. El análisis se ha dividido en dos subperiodos, y se observa que entre finales de los años setenta y principios de los ochenta, la oferta monetaria parecía estar bajo el control discrecional del banco central español. Sin embargo, los cambios a mediados de los años ochenta muestran, por medio de la evidencia, que es posible la endogeneidad de la oferta monetaria en la economía española. 
A partir de entonces, y gracias a las técnicas econométricas que permiten contrastar la existencia de relaciones en niveles de largo plazo y causalidad en el sentido de Granger sin necesidad de conocer el orden de integración de las series utilizadas, se propone que el uso de estas técnicas subsana los dos obstáculos a los que se enfrentan los trabajos mencionados.

Perrotini (2007) describió en "El nuevo paradigma monetario" que un nuevo consenso macroeconómico en torno al Modelo de Inflación Objetivo (MIO) comenzó a emerger hace casi tres décadas y hoy está vigente, de modo explícito o implícito. Se trata de un nuevo consenso a favor de la tesis de que un banco central autónomo que utiliza la tasa de interés como instrumento de la política monetaria puede alcanzar la estabilidad de precios mediante una meta de inflación. Esta estrategia elimina el "sesgo inflacionario" del banco central, descrito por Kydland y Prescott (1977) y Lucas (1996).

El modelo de inflación objetivo se implementa generalmente en la forma de la llamada regla de Taylor. Para el caso de México, Perrotini afirma que el banco central anunció una meta de inflación amplia en 1999 y adoptó el Modelo de Inflación Objetivo completamente en 2001, aunque, en rigor, ya desde 1996 la política monetaria había empezado a orientarse con base en algunas características del nuevo paradigma monetario. Además, sostiene que el modelo de inflación objetivo se constituye en un marco flexible de política monetaria que funciona como un ancla formal de las expectativas de inflación. Es por esto que una regla monetaria describe cómo los instrumentos de esa política deben ajustarse a los cambios de la inflación, del producto interno bruto (PIB) o de alguna otra variable económica relevante.

En el modelo del nuevo consenso monetario, el ancla nominal útil y efectiva debe satisfacer dos funciones importantes: (i) debe ser creíble y transparente y (ii) debe ser flexible para permitir la absorción de choques temporales y mitigar la volatilidad de los ciclos económicos a manera de preservar la estabilidad de precios.

\section{El caso colombiano}

Para el caso colombiano también se destacan algunos trabajos que analizan la política monetaria por medio de la óptica de la regla de Taylor. Se describen a continuación los trabajos que mayor aproximación y pertinencia tienen con los objetivos que se proponen en esta investigación. En el primero de ellos, titulado "Datos en tiempo real: Una aplicación a la regla de Taylor en Colombia”, Gloria Bernal y Johanna Táutiva desarrollan y explican la situación que se da en todos los países, incluido Colombia. Tal situación radica en que con frecuencia se revisan datos macroeconómicos relevantes en la economía luego de ser ya calculados y publicados -en el caso de Colombia, por el DANE-. En su artículo, Bernal y Táutiva ponen de relieve dicho aspecto e intentan determinar la sensibilidad de un modelo de regla de política al uso de datos 
revisados y datos de tiempo real. Los resultados obtenidos evidencian diferencias significativas en las estimaciones y proyecciones de los modelos cuando se usan datos de tiempo real y datos revisados, que pueden afectar las estimaciones de la regla de Taylor. Para Andrés Felipe Giraldo Palomino, autor del artículo "Aversión a la inflación y regla de Taylor en Colombia. 1994-2005”, el país está dentro un contexto sobre la declaración constitucional de la independencia del Banco de la República en 1991 hasta ahora, donde la política monetaria ha sido conducida con el fin de cumplir con el mandato de velar por la estabilidad de precios en concordancia con las demás políticas económicas.

Con el fin de alcanzar dicho objetivo, la Constitución le otorgó al Banco de la República los instrumentos monetarios, cambiarios y crediticios. Además, se especifica que desde el año 2000, la junta directiva del Banco de la República adoptó de manera explícita la estrategia de inflación objetiva. Así, el banco no solo se preocupa por los agregados monetarios y su efecto inflacionario, sino también por variables que, en el momento de formular la política económica, la junta directiva considere importantes para alcanzar su objetivo de inflación. En particular, una de las variables a la que le hace seguimiento es la brecha del producto, definida como la diferencia entre el producto efectivo y el producto potencial.

En el estudio desarrollado por Giraldo estima la aversión a la inflación y a los ciclos por parte del Banco de la República para el periodo 1994-2005. Para esto se usó una estructura espacio-estado y estimado por el método de filtro de Kalman. Se concluye que el parámetro de aversión a la inflación cumple el principio de Taylor (toma un valor mayor a uno), lo cual es acorde con los resultados de Bernal (2002) y de López (2004). Así mismo, se desarrollaron cálculos que determinaron que el parámetro que mide la aversión a la brecha del producto es no significativo, por lo que se constituye que, de acuerdo con la muestra y con la estimación realizada, la única variable a la cual reacciona el Banco de la República es la brecha inflacionaria. Además, el presente trabajo encontró evidencia estadística de capacidad predictiva superior fuera de la muestra para la tasa de cambio nominal para seis de las seis divisas consideradas, esto mediante el uso de los fundamentos de la regla de Taylor.

Por otro lado, Minsky (1990, p. 37) investigó el comportamiento de una economía monetaria con un enfoque, de cierto modo, en el grado de desarrollo financiero y que crece en condiciones de incertidumbre no cuantificable. Su aporte tiene consecuencias, pues induce un ciclo económico por la volatilidad de las expectativas; adicionalmente, los puntos de inflexión en este ciclo endógeno son susceptibles de modificarse mediante el manejo de las políticas monetarias y fiscales cuyo objetivo sea la coordinación para estabilizar los precios de los activos de capital en el mercado financiero. 


\subsection{La política monetaria y el crecimiento: características particulares}

En la investigación se consideró importante desarrollar el contexto en el cual se generó la Constitución Política de 1991. Para empezar, es preciso afirmar que la sociedad estaba cansada de la violencia generada por el narcotráfico, los inicios del paramilitarismo y el terrorismo (resultado de la guerrilla y del paramilitarismo), la corrupción, la segregación, la pobreza, deficiencias en el sistema educativo, discriminación racial, falta de patriotismo generalizado, el cual se reflejaba en la sensación de la no representatividad de la sociedad en los funcionarios del país, entre otras razones. Por tal motivo, un movimiento estudiantil desarrolló un voto no autorizado en los comicios del 11 de marzo 1990, el cual preguntaba si el ciudadano quería una nueva Constitución. Esto fue conocido como la "séptima papeleta" y dio paso al establecimiento de la Asamblea Nacional Constituyente.

La Constitución vigente antes de la de 1991 era la de 1886, que concebía un Estado centralista y católico que buscaba la homogeneización de la población a un patrón de ciudadano colombiano y que daba la espalda a la existencia de otro tipo de comunidades en el país, entre otras razones económicas, cambiarias y crediticias que se profundizarán más adelante. Siendo así, y teniendo en cuenta el conjunto de cambios realizados en la organización del Estado colombiano, la política monetaria constituyó un pilar adicional en la reorientación del contexto y marco legal de los instrumentos con las cuales se dotó la institucionalidad colombiana para hacer uso de sus funciones de acuerdo con sus deberes en el nuevo modelo de desarrollo.

Dadas las características del Banco de la República, se requiere determinar en todo momento, con la mayor precisión posible, la relación entre la demanda de base monetaria y su oferta (Minsky, 1990). Dicha relación es importante cuando la estrategia, como en este caso, se basa en el establecimiento de indicadores cuantitativos y el precio final fluctúa, teniendo como meta intermedia la tasa de interés, y cuando el banco requiere anticipar los flujos de liquidez a corto plazo, como lo explican Hernández y Tolosa (2001).

Dentro de las medidas posibles, al darle un rango a las tasas de intervención, la junta directiva toma en consideración que exista coherencia con los niveles de las tasas de interés externas, las tasas de interés pasivas y activas internas, y las expectativas de devaluación. Siguiendo las ideas de Hernández y Tolosa (2001, si, por ejemplo, la base monetaria se sitúa por encima de la línea de referencia y la tasa de interés interbancaria se reduce hasta la tasa mínima de contracción, el banco absorbe el exceso de liquidez a esa tasa. En el caso contrario, la tasa de interés aumenta y el banco suministra liquidez cuando la tasa de interés interbancaria alcanza la tasa máxima de expansión. Ahora bien, si la base monetaria se desvía de su línea de referencia, la junta directiva, después de evaluar las 
variables que analiza en el proceso de toma de decisiones, puede aumentar o disminuir la tasa de interés de intervención con el fin de corregir dichas desviaciones.

Los cupos de la subasta de expansión o contracción se determinan mediante una doble metodología, como se ve en Hernández y Tolosa (2001 p. 67):

En la primera de ellas, que se usó hasta enero de 2001, al final de cada mes, la Junta analizaba la evolución prevista de la oferta de base monetaria para el mes subsiguiente y la comparaba con la demanda teórica estimada según la senda de crecimiento en igual periodo. Con base en estos estimativos, la Junta determinaba los montos de expansión o contracción a realizarse a través de Operaciones de Mercado Abierto, y autorizaba al Comité de Intervención Monetaria y Cambiaria (CIMC) ${ }^{9}$ para modificar los cupos si se presentaban desviaciones significativas en las proyecciones. A partir de enero de 2001 aparecieron algunas modificaciones al esquema operativo de suministro de liquidez, la Junta asignó al CIMC la tarea de determinar los cupos de Repos y de OMAS, y creó un Comité Operativo Interno $(\mathrm{COI})^{10}$, que puede modificarlos para compensar cambios no previstos en las fuentes de la base $^{11}$.

Se han realizado múltiples estudios acerca de los posibles factores que han determinado el comportamiento de la tasa de crecimiento del PIB. Por ejemplo, en 2009, Carlos Humberto Ortiz, José Ignacio Uribe y Harvy Vivas elaboraron el documento "Transformación industrial, autonomía tecnológica y crecimiento económico: Colombia 1925-2005”, en el que se establece la relación de causación que existe entre la inversión y la dependencia tecnológica con el crecimiento económico. Carlos Humberto Ortiz aporta otro trabajo en compañía de Lina Marcela Vásquez, "Aprendizaje manufacturero, dependencia tecnológica y crecimiento económico", en el que se alude a la misma relación; sin embargo, este último trabajo se centra en los procesos de industrialización y desindustrialización, y en su relación evidente con el crecimiento. José Guillermo García publicó en 2002 "Liberalización, cambio estructural y crecimiento económico en Colombia”, un estudio en el cual relacionó el crecimiento con el cambio estructural del siglo XX hacia la apertura económica y los efectos que trajo en los diferentes sectores. El presente artículo se desarrolla con base en estos documentos.

Basándose en datos del DANE, el comportamiento del PIB en el periodo 1990-2007 anual a precios constantes año base 1994, como se muestra en la figura 2, ha presentado una tendencia creciente, pasando de una producción de 56874 mil millones de pesos en 1990 a una de 100778 mil millones en 2007, un aumento real de la economía de 43 904 mil millones de pesos.

9 El CIMC está integrado por el ministro de Hacienda y Crédito Público o su delegado, el gerente general del BR y los miembros de dedicación exclusiva de la JDBR.

10 El COI está conformado por el gerente técnico del Banco de la República, el subgerente de Estudios Económicos y el subgerente Monetario y de Reservas.

11 El CIMC está integrado por el ministro de Hacienda y Crédito Público o su delegado, el gerente general del BR y los miembros de dedicación exclusiva de la JDBR. 
Figura 2. Producto interno bruto anual 1990-2007

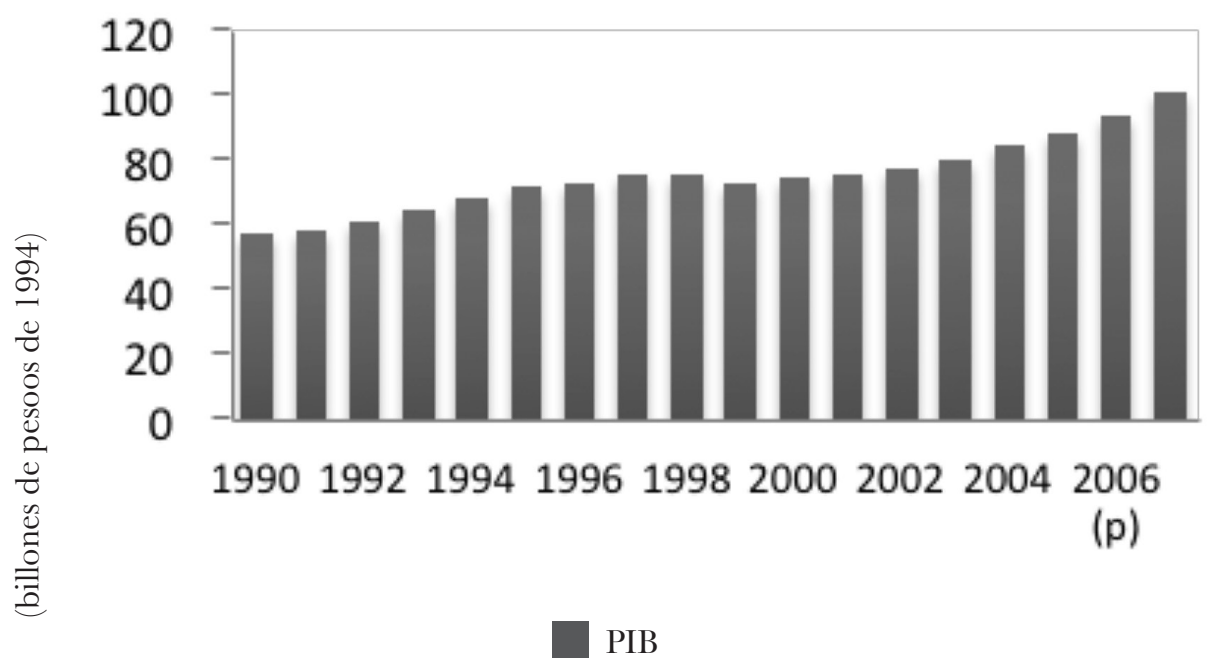

Fuente: DANE- Dirección de Síntesis y Cuentas Nacionales y Banco de la República, Estudios Económicos. Diseño propio.

Es posible observar que, durante el periodo de estudio, en Colombia se mantuvieron tasas de crecimiento positivas, a excepción de 1999, cuando dicho crecimiento se deterioró significativamente. "A finales de los años noventa, los hallazgos de petróleo al principio de esa década y una masiva entrada de capitales revaluaron la tasa de cambio, y un gasto público desbordado terminó por crear una serie de profundos desequilibrios macroeconómicos que se manifestaron al comienzo como burbujas especulativas en los mercados de finca raíz y accionarios" (Kalmanovitz, 2004, p. 98) y terminaron por dejar al país en una situación de vulnerabilidad frente a la crisis internacional desatada por la moratoria rusa de agosto de 1998, como lo afirma Salomón Kalmanovitz. Las deterioradas cuentas fiscales, un sector privado endeudado tanto externa como internamente en grandes magnitudes y la suspensión inesperada del financiamiento externo (Ibíd., p. 99) provocaron una contracción del PIB del 4,2% en 1999, como se presenta a continuación.

Entre 1992 y 1997, la economía mostró tasas de crecimiento promedio superiores al $5 \%$, pero, como ya se explicó, en 1998 se inició una crisis de tal magnitud que no se sentía algo similar desde la Gran Depresión de los años treinta (Kalmanovitz, 2004, p. 99). Consecutivamente, la recuperación que ocurrió y el desarrollo en el país fueron lentos a causa del deterioro de las expectativas de los agentes en medio de la compleja situación económica. Adicionalmente, la política central de la administración de Andrés Pastrana, dirigida a la negociación con las Fuerzas Armadas Revolucionarias de 
Colombia (FARC), dio lugar a una percepción magnificada y generalizada del poder de la insurgencia y al desarrollo de las vías de hecho, que aprovecharon los diálogos de paz para hacer proselitismo armado y deteriorar aún más las expectativas (Kalmanovitz, 2004, p. 99).

García (Kalmanovitz, 2004, p. 99), en su trabajo "Liberalización, cambio estructural y crecimiento económico en Colombia", determinó que, al examinar lo ocurrido en el país con la implementación del modelo institucional de los años noventa, los objetivos de la transformación institucional hacia la economía del mercado, la estabilización monetaria y el control de la inflación, a pesar de haber sido logrados en gran medida, según lo revelan, no dieron un mejoramiento de las condiciones estructurales del sistema productivo para el crecimiento a largo plazo, como teoriza la corriente neoliberal. Eso es evidencia de la evolución de la inversión y de los niveles de desempleo en el país.

Después del intento de reactivación en los años 1997 y 2000, la desaceleración se presentó nuevamente en 1998, pasando de un crecimiento de 3,43\% en el 97 a 0,57 \% en el 98. De igual manera, el crecimiento, que en 2000 fue de 2,92\%, pasó a 1,47 \% en 2001. Finalmente, el gobierno tuvo que ceder ante la realidad de los hechos y aplicar las políticas anticíclicas en 2001.

Figura 3. PIB real colombiano 1990-2007

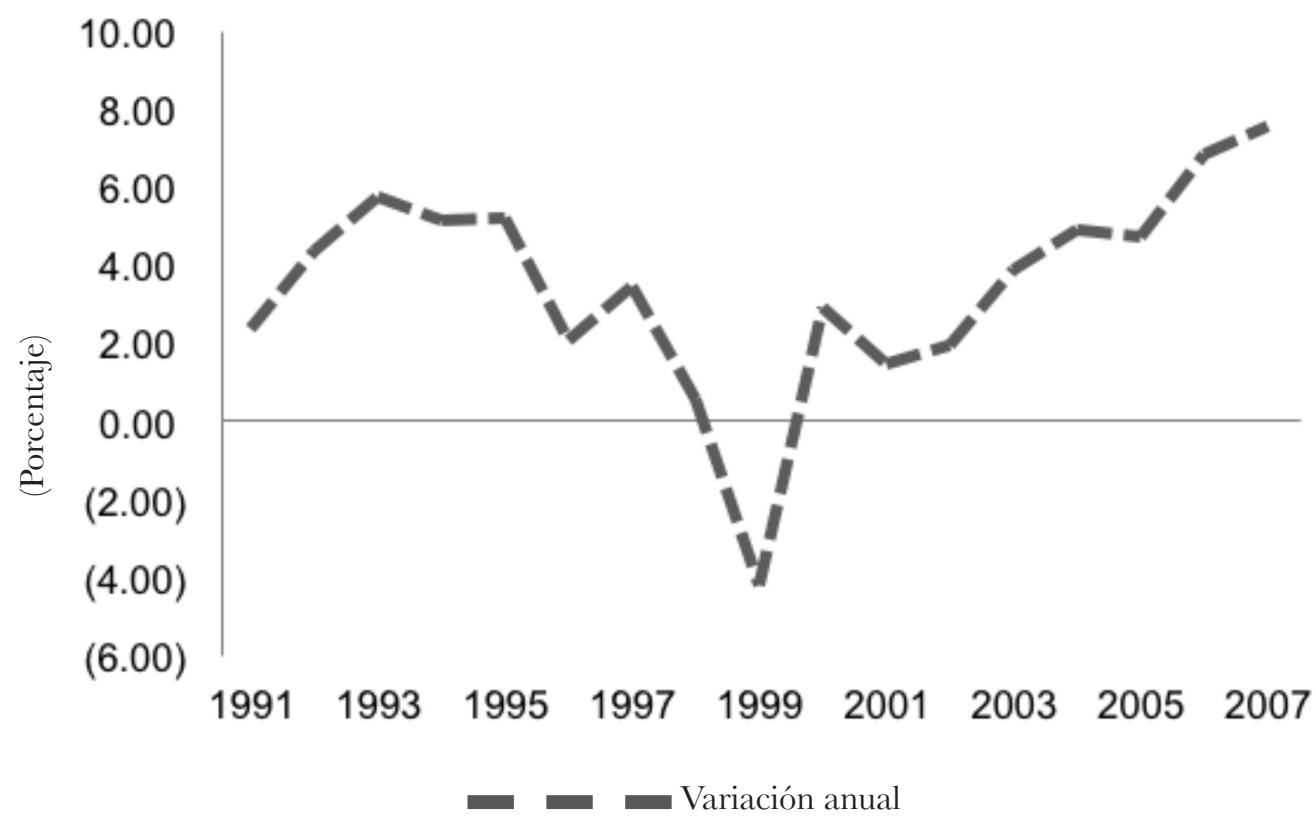

Fuente: DANE- Dirección de Síntesis y Cuentas Nacionales y Banco de la República, Estudios Económicos. Diseño propio. 
Tabla 1. Variación porcentual anual PIB. Ramas de actividad económica (1995-2001).

\begin{tabular}{|c|c|c|c|c|c|c|c|}
\hline $\begin{array}{c}\text { Ramas de actividad } \\
\text { económica }\end{array}$ & 1995 & 1996 & 1997 & 1998 & 1999 & 2000 & 2001 \\
\hline $\begin{array}{l}\text { Agropecuario, silvicultura, } \\
\text { caza y pesca }\end{array}$ & 3,73 & $-1,24$ & 0,65 & 0,04 & $-0,05$ & 3,85 & $-0,36$ \\
\hline $\begin{array}{l}\text { Explotación de minas y } \\
\text { canteras }\end{array}$ & 14,57 & 7,29 & 3,69 & 15,59 & 18,47 & $-10,28$ & $-6,11$ \\
\hline Electricidad, gas y agua & 2,58 & 4,90 & 0,96 & 1,76 & $-4,18$ & 0,89 & 3,05 \\
\hline Industria manufacturera & 5,54 & $-1,38$ & 0,51 & $-0,24$ & $-8,55$ & 11,80 & 1,33 \\
\hline Construcción & 1,90 & $-12,94$ & 2,18 & $-7,23$ & $-27,00$ & $-3,89$ & 3,86 \\
\hline $\begin{array}{l}\text { Comercio, reparación, } \\
\text { restaurantes y hoteles }\end{array}$ & 3,83 & $-0,91$ & 1,68 & $-1,60$ & $-15,44$ & 7,34 & 3,11 \\
\hline $\begin{array}{l}\text { Transporte, almacenamiento } \\
\text { y comunicación }\end{array}$ & 6,51 & 3,83 & 5,82 & 2,49 & $-1,92$ & 1,53 & 4,00 \\
\hline $\begin{array}{l}\text { Establecimientos financieros, } \\
\text { seguros, inmuebles y servicios } \\
\text { a las empresas }\end{array}$ & 8,63 & 5,17 & 4,92 & $-1,28$ & $-4,94$ & $-0,98$ & 2,23 \\
\hline $\begin{array}{l}\text { Servicios sociales, comunales } \\
\text { y personales }\end{array}$ & 8,96 & 16,18 & 7,19 & 1,81 & 3,25 & 0,59 & 0,73 \\
\hline Producto interno bruto & 5,20 & 2,06 & 3,43 & 0,57 & $-4,20$ & 2,92 & 1,47 \\
\hline
\end{tabular}

Fuente: DANE- Banco de la República.

Desde el punto de vista de las ramas de actividad económica, el modelo de apertura neoliberal de los años noventa provocó desempeños desiguales en los diferentes sectores, con resultados asimétricos a raíz de la liberalización, sobre todo por la dependencia que existía en la mayoría de los sectores de las políticas públicas (García, 1995, p. 238). Como se observa en la tabla 1, todos los sectores presentan una tendencia de desaceleración en la segunda mitad de la década de los noventa, lo que revela una caída significativa del crecimiento, a excepción del sector de "explotación de minas y canteras", que no presentó deterioro en este periodo, aunque su desempeño no depende, como otros, del entorno macroeconómico e institucional, sino de los precios del exterior (Ibíd., p. 238).

Los sectores que se afectaron por la reforma, según la evidencia, fueron la construcción, que presentó los mayores decrecimientos del periodo (-12,94 \% en 1996 y -27 \% en 1999), la industria manufacturera y la agricultura, que también presentaron bajas 
variaciones negativas en algunos años. Las afectaciones se dieron por motivos diferentes: en la construcción se dio al enfrentar la dinámica recesiva de la economía y el cambio de las pautas de financiamiento de los negocios en el sector, haciéndose más complicado el apalancamiento financiero como consecuencia del debilitamiento de los instrumentos del crédito de largo plazo, fundamentales para el mercado de vivienda. Sin embargo, todos los sectores se vieron afectados por un encadenamiento entre los sectores mencionados (de producción material); y las actividades de intermediación y servicios, a pesar de haber crecido a tasas superiores al $4 \%$ en la primera parte de la década, cayeron en la dinámica recesiva del ciclo (García, 1995, p. 240)

El indicador de transformación industrial ${ }^{12}$ es adecuado para el caso colombiano. Desde los años treinta hasta los setenta, la estructura industrial del país se diversificó, la creación de plantas industriales aumentó tendencialmente y la industria manufacturera creció más rápidamente que el resto de la economía, es decir, se dio una industrialización; por el contrario, desde los años ochenta, la diversificación industrial sufrió un estancamiento, la creación de plantas industriales disminuyó tendencialmente y la industria manufacturera perdió participación en el PIB y creció más lentamente que el resto de la economía, por lo tanto, se dio una desindustrialización, como lo afirman Ortiz et al. (2009, p. 2).

Otra característica de la economía colombiana que también ha tenido incidencia en su crecimiento es el alto grado de dependencia tecnológica. A pesar de que el problema ha sido identificado y de que se dio paso a la creación de COLCIENCIAS ${ }^{13}$, la dependencia tecnológica nacional ha aumentado (Ibíd., p. 2). El verdadero cambio estructural de la economía colombiana hacia 1980 consistió en la adopción de un modelo de desarrollo que renunció a la autonomía tecnológica. Se ha argumentado que esa característica, estrechamente imbricada con la desindustrialización nacional, ha contribuido a explicar la desaceleración económica de Colombia (Ortiz y Vásquez, 2007, p. 20).

Con la nueva orientación, a la cual nos referimos en el apartado de apertura comercial, la tasa de crecimiento del sector industrial manufacturero cayó por debajo del promedio nacional. A pesar de esta tendencia, el sector productor de materias primas, bienes intermedios, no disminuyó su tasa de crecimiento tan rápido como los demás subsectores manufactureros, y mantuvo una participación en el PIB alrededor del 8 \% (Ortiz et al., 2009, p. 21). Aun así, el sector industrial manufacturero, en general, perdió peso relativo, pasó de generar el 22.5 \% del PIB en 1980 a generar el 13.5 \% en 1999, como se observa en la figura 4.

12 En la literatura de proceso de industrialización se utiliza generalmente como indicador de transformación industrial la variación sostenida de la participación del sector manufacturero en la generación del PIB. Si la variación es positiva, se habla de industrialización; y si es negativa, se habla de desindustrialización. Ortiz (2009).

13 Departamento Administrativo de Ciencia, Tecnología e Innovación. 
Figura 4. Participación porcentual en la generación del PIB por ramas de actividad económica, 1999.

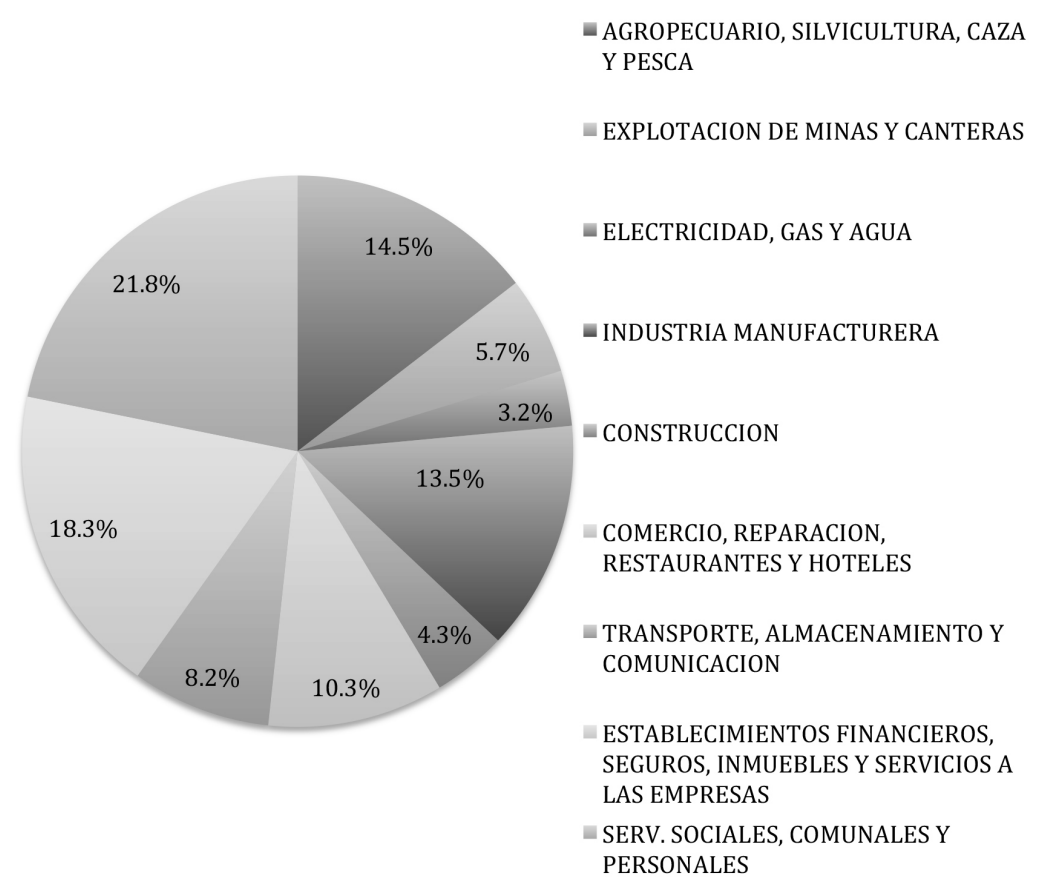

Fuente: DANE- Banco de la República. Diseño propio.

En el contexto institucional creado por la apertura, la dinámica monetaria fue un factor determinante del desequilibrio comercial y de cuenta corriente hasta 1998 (García, 1999, p. 98). La revaluación marcó el ciclo de debilitamiento del aparato productivo colombiano al igual que en los años ochenta (Cuevas, 1986 citado en García, 2002, p. 193). Esta dinámica se manifestó en la desaceleración y crisis de los principales sectores de producción material, como ya se había mencionado: la agricultura, la industria manufacturera y la construcción. Los efectos específicos en la industria se reflejaron en la desaceleración del ritmo de crecimiento en el sector después de 1995.

Un nuevo estancamiento industrial se dio en el periodo 2000-2005. En este periodo, todos los subsectores manufactureros mantuvieron su contribución en la generación del producto interno bruto: los bienes intermedios, alrededor del $8 \%$; la agroindustria, aproximadamente el $6 \%$; los bienes de capital el $1 \%$ y la industria manufacturera total generó el 15 \% del PIB (Ortiz et al., 2009, p. 22).

La evolución del flujo de capitales provenientes de endeudamiento externo en Colombia presentó características y fluctuaciones asociadas a factores externos e internos. Siguiendo a Rubio (2003, p. 5): 
Entre los factores externos destacan las crisis cambiarias y financieras ocurridas en la década de los noventa, que afectaron a países como México y Argentina. Entre los factores internos se acentúan las políticas económicas implementadas para el manejo de los desequilibrios y ajustes en las cuentas fiscales, la balanza de pagos y la tasa de cambio, así como las reformas estructurales iniciadas en los primeros años de la década del noventa.

El endeudamiento externo colombiano en el periodo de estudio parte de una etapa donde la estructura se afectó según las fuentes de financiamiento, las condiciones financieras, los plazos, entre otros. Rubio sugiere cinco etapas de evolución del endeudamiento externo en Colombia. En lo concerniente al periodo de estudio, se tendrá en cuenta desde la tercera etapa. Se cita a continuación la descripción de dichas etapas, de nuevo con base en Rubio (2003, p. 5).

- En el periodo 1988-1992, los flujos de deuda externa se estancaron y la política de financiamiento del sector público se reorientó hacia la sustitución de deuda externa por deuda interna. Este cambio coincidió con el inicio del programa de apertura económica en Colombia.

- Entre 1993 y 1998, en el marco de la política de internacionalización de la economía colombiana, la deuda se incrementó de manera sustancial, coincidiendo con el notable crecimiento del gasto privado.

- 1999-2002. Como consecuencia de la crisis financiera internacional iniciada a finales de 1997, los flujos de deuda externa disminuyeron ostensiblemente, en particular los del sector privado, especialmente a partir de 1999. A su vez, la inversión privada y el crecimiento del PIB presentaron una notable disminución, mientras que la deuda externa pública se incrementó como consecuencia de los mayores déficits fiscales.

\subsection{Crisis en el periodo de estudio}

En el periodo de estudio, desde 1990 hasta 2010, se presentaron dos eventos que llaman la atención en el análisis del crecimiento económico, ambos con una reducción importante de la tasa de crecimiento del PIB, dos crisis económicas que tuvieron impacto en el país. La primera ocurrió a finales de los años noventa, a la cual ya nos referimos, que se originó en las economías emergentes de Asia y que luego se extendió a Rusia, a Brasil y, eventualmente, a todos los mercados emergentes en un marco de la apertura económica. La segunda crisis se originó en la caída del sistema financiero en varios países desarrollados por la crisis financiera internacional.

En este apartado se establece un paralelo de la situación económica coyuntural en cada una de estas crisis. Así mismo, se mencionan las medias tomadas por el gobierno después 
de la crisis del noventa y aquellas que se tomaron para contrarrestar los choques provenientes de la reducción de la demanda mundial a raíz de la crisis financiera.

La crisis financiera internacional tuvo repercusiones en la economía colombiana con mayor profundidad en 2009. Como se observa en la figura 5, la tasa de crecimiento del PIB empezó a caer después de 2007, la desaceleración se percibió en 2008, pasando de una tasa de crecimiento de $6,9 \%$ (la más alta que se registró en todo el periodo) a una tasa de 3,55\%. Finalmente alcanzó una desaceleración, llegando en 2009 a 1,65 \%, la cual, comparada con la contracción de 1999, fue de -4,2\%.

Figura 5. PIB real colombiano 2001-2012

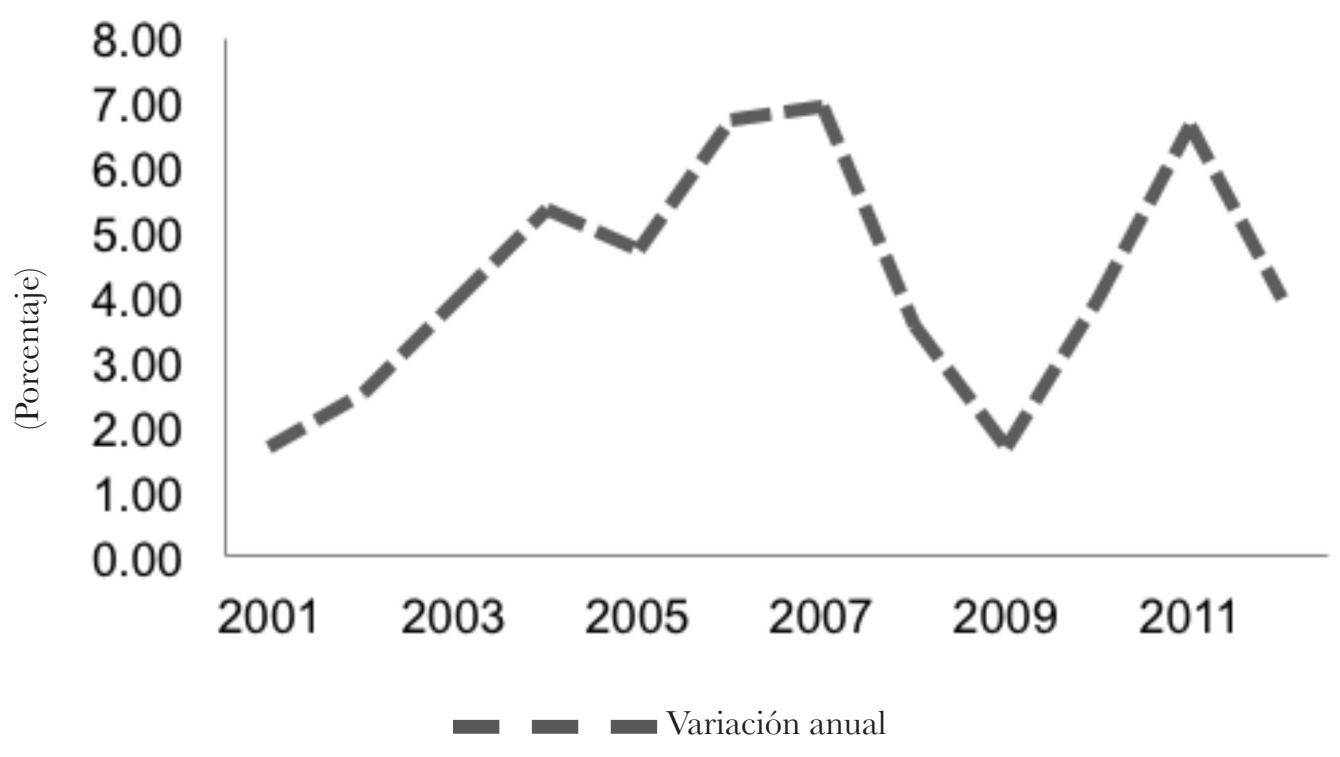

Fuente: DANE- Dirección de Síntesis y Cuentas Nacionales y Banco de la República, Estudios Económicos. Diseño propio.

Las condiciones iniciales en ambos casos fueron muy diferentes. La tabla 2 muestra algunas variables macroeconómicas y financieras que permiten dar una idea de la situación de dos años previos a las dos crisis. De acuerdo con Steiner (2009, p. 12), “(...) La situación en los años noventa es evidentemente más frágil en comparación con la experiencia del 2008, tanto en el frente fiscal, así como en el cambiario y financiero".

Tanto el endeudamiento externo del sector público como el del privado eran más altos a finales de los años noventa que en la segunda mitad de la primera década del siglo XXI. Por otra parte, mientras que en los años noventa Colombia, al igual que muchos otros países latinoamericanos, perdió acceso al financiamiento externo, para 2008 los 
mercados financieros externos se mantuvieron abiertos, especialmente para la emisión de deuda pública de bonos soberanos con buena calificación crediticia (Steiner, 2009, p. 13). Adicionalmente, como se estableció en los antecedentes de este trabajo, en la última década del siglo XX el país contaba con un régimen cambiario bastante inflexible basado en la "banda cambiaria", y desde finales de 1999, el Banco de la República ha funcionado bajo el esquema de inflación objetivo, con tasa de cambio flexible. Del mismo modo, en la última crisis, la calidad de la cartera del sistema financiero fue mejor y estuvo mucho más provisionada que en la crisis anterior (Ibíd., p. 13)

Tabla 2. Comparación de variables económicas

\begin{tabular}{|l|c|c|c|c|}
\hline & \multicolumn{2}{|c|}{ Finales de los 90 } & \multicolumn{2}{c|}{ Crisis de 2008 } \\
\hline & Año -2 & Año -1 & Año -2 & Año -1 \\
\hline Deuda externa (\% del PIB) & 28,1 & 32,8 & 21,4 & 19,3 \\
\hline Pública (\%del PIB) & 14,4 & 16,0 & 7,6 & 7,0 \\
\hline Privada (\%del PIB) & 13,7 & 16,8 & 13,9 & 12,2 \\
\hline Balance en cuenta corriente (\% del PIB) & $-4,3$ & $-4,8$ & $-1,8$ & $-2,8$ \\
\hline Inflación (\%) & 20,8 & 18,5 & 4,3 & 5,5 \\
\hline Calidad de cartera- Sistema financiero (\%) & 7,4 & 8,7 & 3,0 & 4,0 \\
\hline Cubrimiento de cartera- sistema financiero (\%) & 30,2 & 28,8 & 132,2 & 113,0 \\
\hline
\end{tabular}

Fuente: Banco de la República, DANE y Superfinanciera. Tomado de Steiner (2009, p. 13).

En el campo fiscal, después de la recesión de 1999, el país tomó medidas que contribuyeron a un mejor desempeño en distintas dimensiones del sector público. En Zuluaga (2009, p. 17) se exponen cifras que respaldan estas afirmaciones:

"El sector público consolidado pasó de un déficit de 3,2 \% a 0,1 \% del PIB en 2008”. Un avance asociado a un aumento del superávit primario del sector público no financiero, posibilitando una reducción considerable de la deuda neta de este.

"En dicho periodo, el superávit primario del SPNF pasó de 1,1 \% a 3,6 \% del PIB, y la tendencia creciente de la deuda se reversó, cayendo esta de 38,2 \% a $24 \%$ del PIB".

"De otra parte, el déficit total del GNC ha disminuido, y el balance primario [de este] pasó de ser deficitario en 2002 (1,8\% del PIB) a ser superavitario en 2008”. (0,9 \% del PIB)".

Estos logros son reflejo del aumento de los ingresos y la disminución del gasto. Entre 2000 y 2008, los ingresos del Gobierno nacional central aumentaron 2,7 \% del PIB y los gastos se recortaron $0,3 \%$ del PIB. El aumento de los ingresos en este periodo fue consecuencia de la dinámica de la inversión, del incremento del recaudo tributario con 
la implementación del impuesto al patrimonio y de la reducción de la evasión; adicionalmente, por el alza del precio internacional de los commodities (Ibíd., p. 18).

Puesto que las condiciones en las que se dieron las dos crisis fueron diferentes, las políticas que el gobierno asumió, tanto en el frente fiscal como en el monetario y cambiario, fueron, así mismo, distintas. En la crisis de los noventa, la política pública se instrumentó orientada necesariamente a evitar una devaluación significativa, lo cual puso en aprietos al gobierno y al sector privado por su alto endeudamiento en moneda extranjera. De igual manera se direccionó a reducir significativamente el déficit en cuenta corriente, a reducir la necesidad de tener que recurrir al financiamiento externo. Para lograr tales objetivos, se recurrió a instrumentos de política de tipo restrictivos, como mayores tasas de interés por el lado monetario y contracción del gasto público (especialmente en inversión) en el frente fiscal. Sin lugar a dudas, la única postura posible para la política pública ante la crisis externa era de carácter evidentemente contraccionista y, por consiguiente, totalmente procíclica (Steiner, 2009, p. 13).

Caso contrario ocurrió al contar con un régimen cambiario flexible, además de un ambiente de baja exposición al riesgo cambiario y con acceso al financiamiento externo, entorno en el cual fue posible definir una estrategia de política pública totalmente diferente. En esta oportunidad fue factible permitir una fuerte devaluación, lo cual evitó tener que subir las tasas de interés. De hecho, estas últimas fueron reducidas de manera significativa. Y en cuanto al campo fiscal, el contar con acceso a financiamiento externo permitió aumentar el déficit fiscal en momentos en que el ciclo económico lo demandaba (Steiner, 2009, p. 14).

Para desarrollar una aproximación de la exogeneidad o endogeneidad de la política monetaria nacional, este estudio estimó la regla de Taylor con datos revisados por parte de las instituciones encargadas (DANE y Banco de la República). En este orden de ideas, como resultado de la exploración econométrica se destaca la aplicación de una metodología de cálculo que consistió en emplear los métodos de mínimos cuadrados ordinarios $(\mathrm{MCO})$ y vectores autorregresivos (VAR). Los parámetros de selección de uno de estos instrumentos se presentan en el desarrollo del apartado de análisis econométrico. Aplicando estas consideraciones, se presentan a continuación los resultados, el proceso de desarrollo de la estimación empírica de la regla de Taylor y sus principales características.

Las cifras con las cuales se estimará el modelo presentan las siguientes características. Por un lado, el IPG se encuentra desde años anteriores a 1990, pero, por otro lado, el PIB trimestral se encuentra desde 1993, ya que se comenzó a aplicar esta metodología desde ese año, justificándolo en la necesidad de cifras de corto plazo en las cuales se observan cambios en el ritmo de crecimiento de la economía, el cual es necesario conocer en forma oportuna, como es afirmado por el DANE en la metodología de cálculo de las 
cuentas trimestrales ${ }^{14}$. Bajo esta parametrización, las variables que tienen una periodicidad mensual, como las variaciones del IPC y la tasa de intervención, se promediaron por tres meses, normalizando y estandarizando las cifras para un modelo que cubrirá el periodo 1993-2012.

Para generar el análisis econométrico, se presentan a continuación las series que se introducirán en el modelo. Respecto a la variable independiente del modelo planteado, la tasa de interés de intervención presenta un comportamiento descrito en la figura 6 , en la que se observa el resultado de la aplicación de las políticas que responden al nuevo marco jurídico de la Banco de la República, donde la disminución de la tendencia es significativa debido, en mayor medida -y como es afirmado por Oscar Iván Zuluaga-, a la disminución de la inflación (Zuluaga, 2009, p. 30).

La estrategia de inflación -objetivo que siguen algunos países- se apoya en el supuesto decisivo de que la autoridad monetaria ejerce una importante influencia sobre el conjunto de tasas de interés de la economía, como se explicó en el primer apartado, cuando se daba un contexto teórico para la tasa de interés, entre otras variables. Esta influencia la realiza la autoridad por medio de los movimientos en las tasas de intervención que dicta la regla de política. El Bank of England Quarterly Bulletin sugiere que las tasas oficiales afectan, además de las tasas de interés de mercado, los precios de los activos, las expectativas de inflación y el tipo de cambio, todas estas con efectos tanto en la demanda doméstica como en la demanda externa neta (Bank of England Quarterly Bulletin, 1999, citado en Arango et al., 2006). Mishkin (1995), por ejemplo, da por sentada la influencia de la política monetaria en la tasa de interés y, con base en ello, presenta un argumento conocido como el canal de tasa de interés, por medio del cual la política monetaria afecta la actividad económica.

Figura 6. Tasa de interés de intervención. 1993-2012. Trimestres.

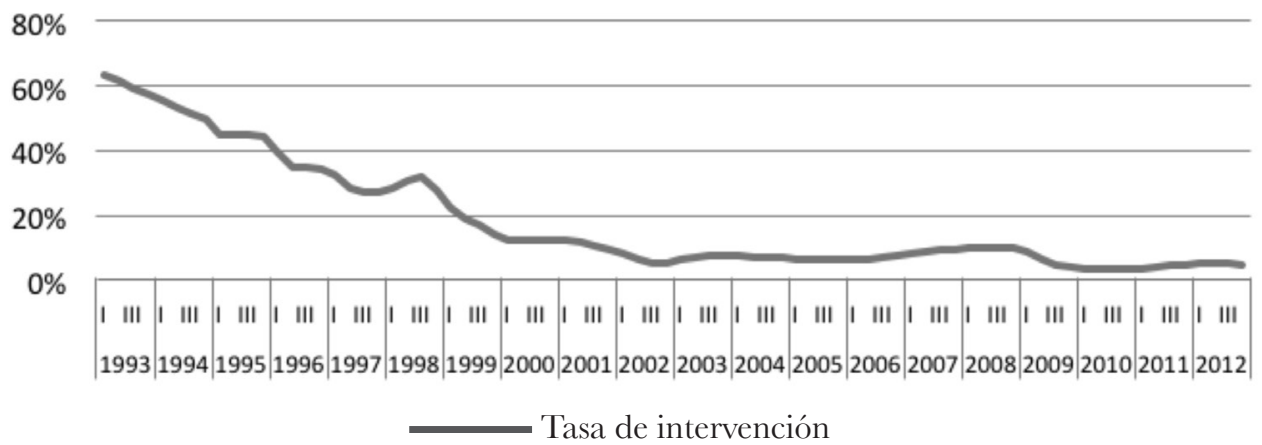

Fuente: Banco de la República.

14 Departamento Administrativo Nacional de Estadística DANE. Ficha metodológica cuentas trimestrales. Recuperado de http://www.dane.gov.co/files/investigaciones/fichas/pib/Ficha_met_cuentas_trimestrales_08_13.pdf 
Así mismo, dicho conjunto de tasas de interés incluye la tasa interbancaria, certificados de depósito a término, la tasa de los créditos de consumo, hipotecas, etc. Y como lo explican Arango et al. (2006), suponiendo que las tasas de interés tengan un componente asociado a la tasa de interés real y otro a las expectativas de inflación, se puede explicar que, mediante los movimientos en las tasas de intervención, la autoridad monetaria puede afectar la trayectoria de las expectativas de inflación futura y, por medio de estas, la propia inflación futura.

La figura 7 representa las tasas de crecimiento desde 1993 hasta 2012. En ella se observan los principales resultados de las coyunturas económicas, por ejemplo, para los años de 1998-II, 1999-II, 2002-I y 2008-II. Este comportamiento, el cual teóricamente es denominado como cíclico económico y que es descrito en el PIB trimestral, representa las dinámicas dentro del periodo que se tendrá en cuenta en la econometría.

Figura 7. Comportamiento del crecimiento del PIB trimestral. 1993-2012.

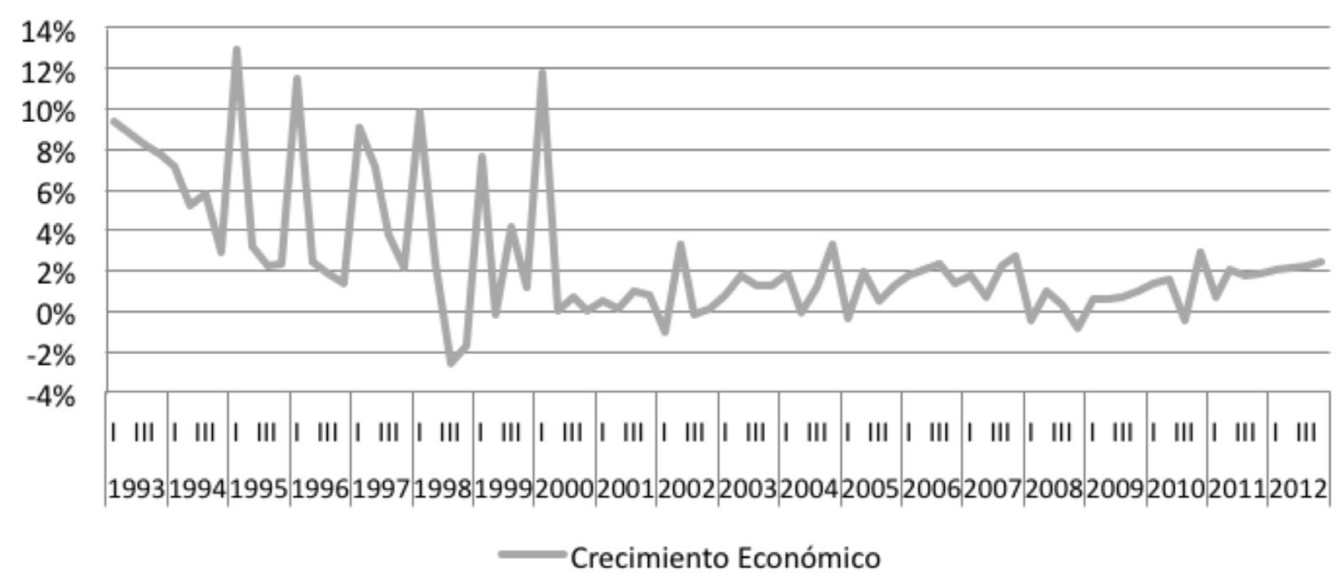

Fuente: DANE.

En la figura 8 se observa el comportamiento del IPC, que teóricamente, y bajo las doctrinas expuestas en el apartado de referentes teóricos y conceptuales, puede estar relacionado con la determinación de la tasa de interés de intervención.

De esta manera, y finalizando la presentación general del comportamiento de los datos que se van a utilizar en el modelo, se procede a continuación a desarrollar el análisis econométrico. 
Figura 8. Comportamiento del IPG 1993-2012. Trimestral.

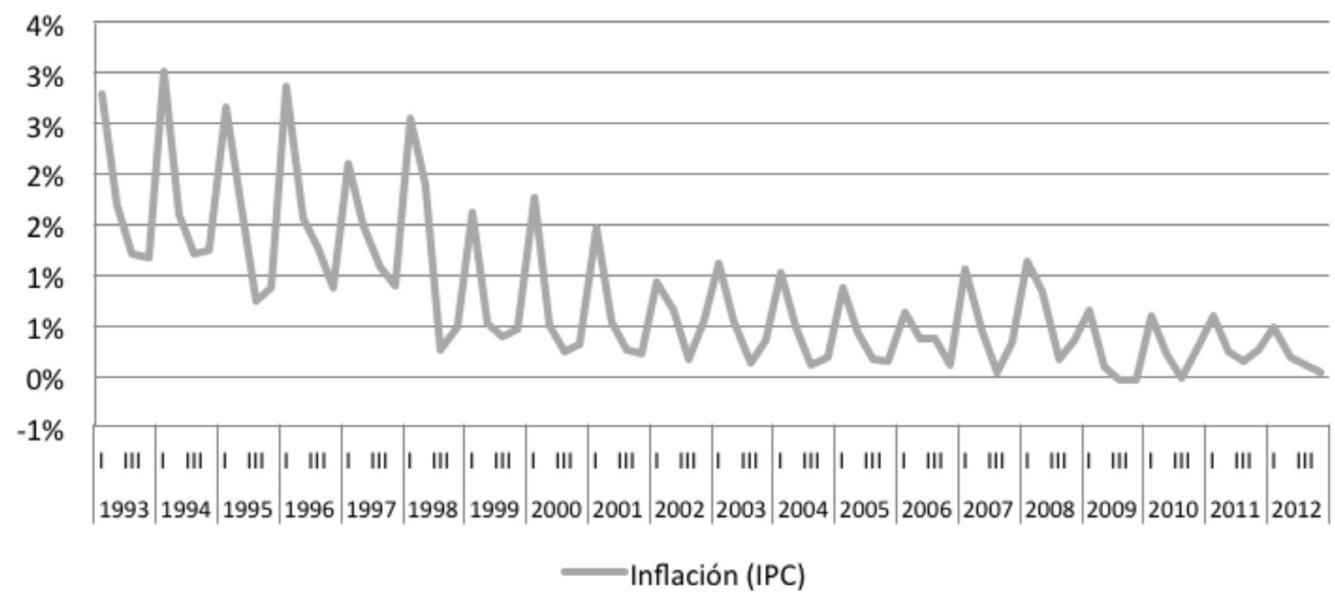

Fuente: DANE.

\section{Resultados econométricos}

Con base en la lectura de casos como el Banco Central Europeo (2008), el Banco Central de la República Dominicana (2013) y los modelos realizados para Colombia, se ha podido establecer que es viable estimar la regla de Taylor utilizando modelos de Data Panel, GVAR, ARIMA y VAR. La aplicación de cada uno de esos modelos depende de las características mismas de los datos. No existe un consenso de obligatorio cumplimiento. De acuerdo con los objetivos establecidos en el inicio de la investigación, el fin de esta sección es realizar un análisis con base en instrumentos econométricos proporcionados, análisis que se inicia con la determinación del modelo que se va a estimar.

Se establece que el método más adecuado es el de vectores autorregresivos, similar a los que existen en la literatura, comenzando con Sims desde 1992, y aplicaciones de este instrumento en documentos de Andrés Giraldo, entre otros. El objetivo de esta metodología de modelaje con VAR propuesta por Sims fue el de alejarse de las restricciones que se imponen a los parámetros en la estimación tradicional. En esta metodología todas las variables dependen de todas.

En este enfoque ni siquiera se hace hincapié en la eliminación de rezagos no significativos, ya que las pruebas usadas pueden resultar poco confiables por la multicolinealidad que suelen exhibir las variables explicativas del VAR. (Montenegro, 2010, p. 140).

Es más, quienes proponen esta metodología sugieren que "no se hace necesario restar tendencias o desestacionalizar las variables no estacionarias, dado que el objetivo 
primordial es descubrir relaciones entre variables más que realizar estimaciones precisas de parámetros" (Ibíd., p. 140). De acuerdo con los investigadores que han usado los vectores autorregresivos, se puede establecer que, como explican Álvarez de Toledo $e t$ al. (2006, pp. 37-66):

La técnica VAR ofrece la posibilidad de analizar las interrelaciones dinámicas existentes entre un conjunto de variables, lo que le confiere mayores posibilidades para analizar y contrastar modelos teóricos.

Como puso de manifiesto Sims (1980, citado en Álvarez de Toledo et al., 2006):

El interés de estimar un modelo VAR también reside en el tipo de información que se deriva del sistema de ecuaciones que se estima. Por ejemplo, a partir de las funciones impulsorespuesta se pueden analizar el signo, la intensidad, el timing y la persistencia que cada una de las innovaciones estocásticas tiene sobre las variables del modelo.

Otro elemento básico del análisis VAR lo constituye la descomposición de la varianza del error de predicción, a partir de la cual se puede estudiar el peso relativo de cada perturbación en la variabilidad temporal de las variables endógenas del modelo (Álvarez de Toledo et al., 2006). En este sentido, cabe aclarar que la metodología VAR no se aplica para realizar predicciones, por tal motivo, es incorrecto efectuar simulaciones a partir del sistema de ecuaciones que resultan de la aplicación del modelo, puesto que dichas predicciones resultarían ser imprecisas, y lo que se busca con la aplicación de esta metodología, como se explicó anteriormente, es descubrir las relaciones existentes entre las variables. De allí que, para tener un mayor acercamiento a la relación de causalidad entre estas, se recurre a la función de impulso-respuesta, y las predicciones se hacen con base en esta misma, tal como se desarrolla a lo largo de este acápite.

\subsection{Aplicación de los vectores autorregresivos}

Varios temas llaman la atención. Primero, la econometría arroja y respalda el desarrollo de los referentes teóricos, como se afirmó. Por ejemplo, al analizar los resultados de la primera aproximación, el modelo de MCO no es explicativo, lo que respalda la hipótesis de que, para ser determinada, la tasa de interés de intervención depende del crecimiento económico y de la tasa de inflación; adicionalmente, sugiere que existe una causalidad inversa en un periodo de tiempo determinado. Lo anterior significa que no tiene representada el modelo de MCO aplicado debido a que, desde los supuestos en la planeación de esa metodología, se elimina la posibilidad de autocorrelación, multicolinealidad u otro comportamiento entre variables que asemeje a la endogeneidad de las variables explicativas. Debido a esto, el modelo logra un coeficiente de ajuste bajo ${ }^{15}$.

15 Entendido como el porcentaje que, de la varianza total, supone la varianza explicada por la regresión. 
Bajo este contexto, se prevé que existe una relación mutua de interdependencia entre las series económicas de este estudio. Ahora bien, la alternativa más apropiada es estimar un sistema de ecuaciones que refleje las relaciones de interdependencia o causalidad que pueden darse entre las variables. En ese sentido, es necesario distinguir entre variables endógenas y variables predeterminadas. Esta distinción tiene una cierta base en la dirección de la causalidad de las variables y está inspirada en las relaciones sugeridas por la teoría económica, como se ha mencionado.

Para el caso de la regla de Taylor, el planteamiento teórico sugiere que la tasa de intervención dada por el Banco de la República es una variable explicada por medio de la tasa de crecimiento exógena al modelo y a la inflación, con las mismas características. Pero la teoría no sugiere una especificación concreta entre variables, como el sentido o la dirección de la causalidad. Al mismo tiempo, no establece parámetros en cuanto al tiempo al incluir variables con retardos, por lo tanto, el planteamiento temporal del modelo se hace subjetivo.

Teniendo en cuenta todo lo anterior, en este modelo se corrieron dos versiones. En ambas se hacen las pruebas de raíz unitaria, histograma y de Akaike y Schwarts, con el fin de determinar la conveniencia de la metodología y el número de rezagos por incorporar. A partir de este modelo, el ajuste aumenta no solo para entender el modelo de intervención, sino para establecer que el crecimiento puede ser explicado mediante la variable política monetaria. Así mismo, los resultados de los análisis de impulso respuesta muestran los comportamientos esperados desde el punto de vista de la teoría, como se observa en la figura 9 . 


\section{"ĆlF́E 25}

ISSN: 0124-3551 / Año 16, No 25 / julio-diciembre / pp. 71-122

Figura 9. Análisis impulso respuesta

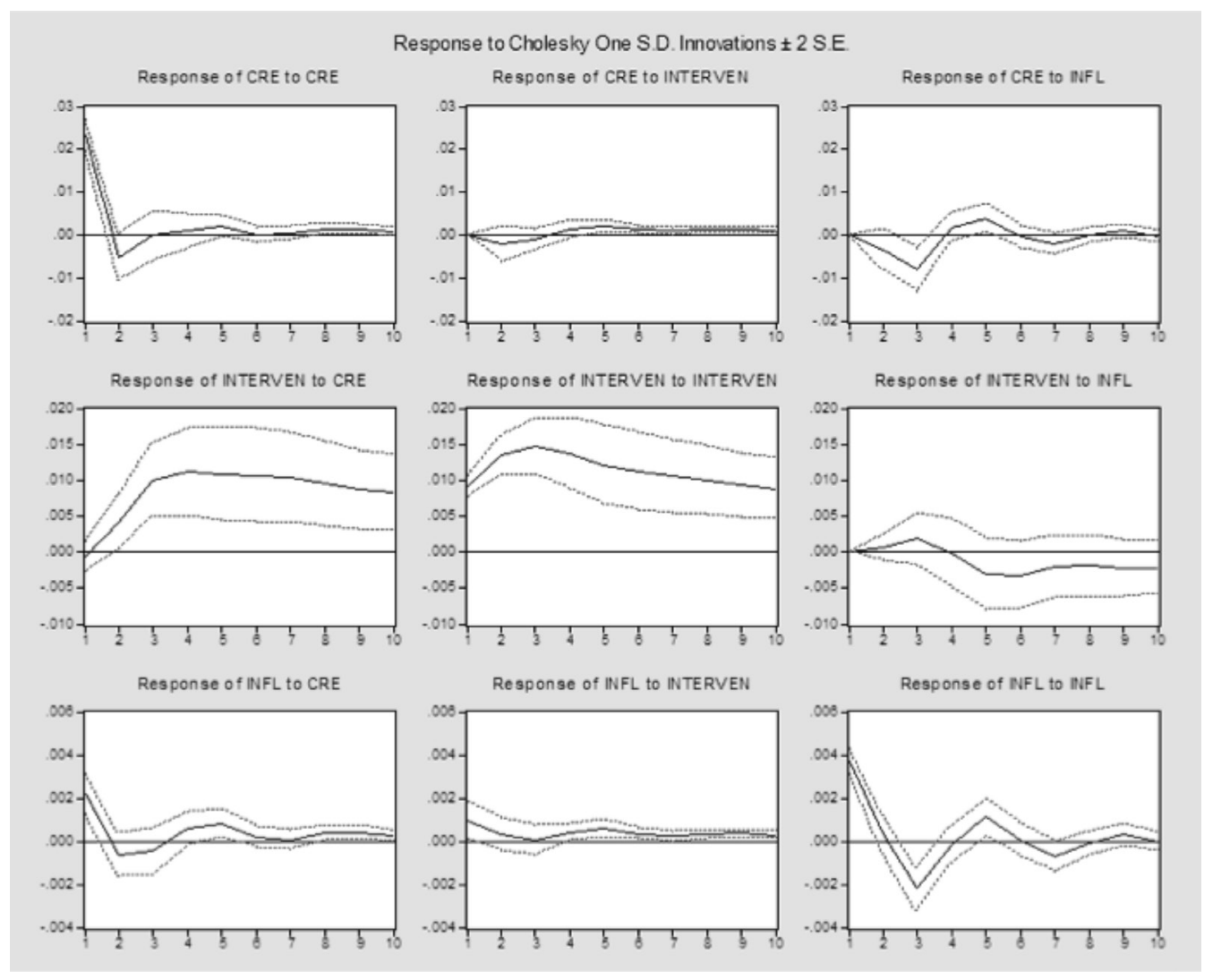

Fuente: EViews 
La función impulso-respuesta presenta la reacción de las variables explicadas en el sistema ante cambios en los errores. Un cambio en una variable en el periodo i afectará directamente a la propia variable y se transmitirá al resto de variables explicadas por medio de la estructura dinámica que representa el modelo VAR. Es decir, ante un aumento del crecimiento económico, la intervención aumenta; y, al mismo tiempo, si incrementa la inflación, la intervención también lo hace. De la misma manera se aplica el análisis de descomposición de la varianza, anexo 2, que, al igual que el análisis de impulso respuesta, permite examinar las interacciones dinámicas que caracterizan el modelo estimado. Dado esto, se permite identificarlas con la simulación del modelo, y con esta se pretende analizar los efectos que las variaciones de las variables exógenas provocan en las variables endógenas.

Por otro lado, de este ítem se puede destacar, como se observa en la figura 10, que el crecimiento depende, en mayor medida, de su propio rezago y de la inflación en un $20 \%$, pero los efectos de la intervención son de largo plazo, puesto que esta variable va tomando mayor relevancia con el paso del tiempo. Es evidente, entonces, que el mayor efecto en la tasa de intervención está dado por sí misma, pero, adicionalmente, tiene un efecto considerable tanto en la inflación como en el crecimiento, lo cual confirma que se trata de una variable que es endógena al modelo.

Además de lo anterior se corrieron las pruebas de cointegración, presentadas en el anexo 3. El resultado obtenido es que no existen valores significativos dentro de estas ecuaciones. Por tal motivo, se puede afirmar que el modelo no requiere transformaciones posteriores, por ejemplo, convertirlo en un Modelo de Vectores de Corrección de Error (VEG).

Figura 10. Análisis de descomposición de la varianza

Descomposición GRE

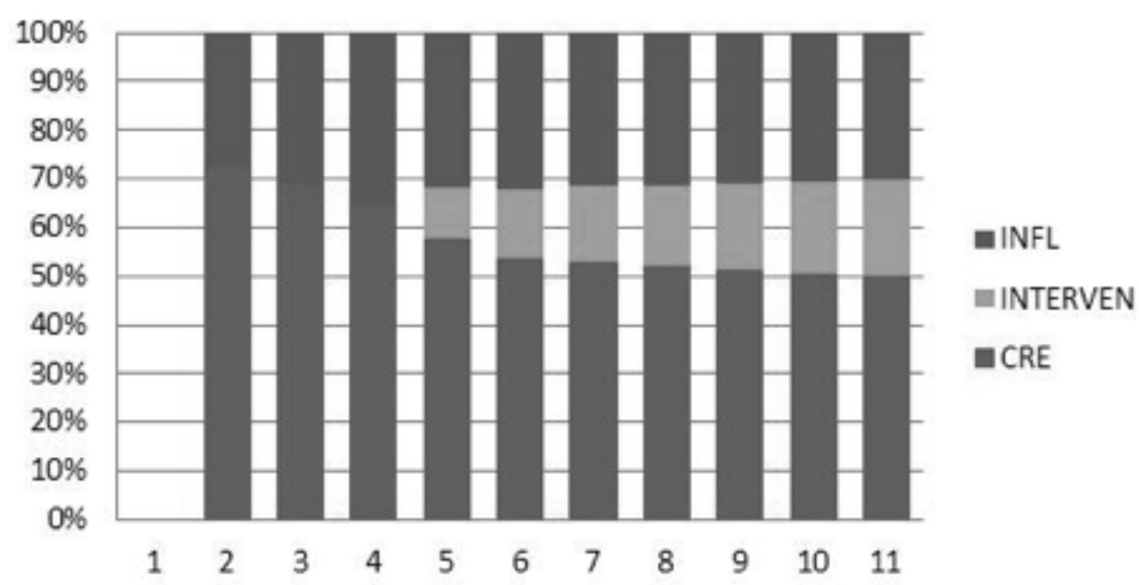




\section{Descomposición INTERVEN}

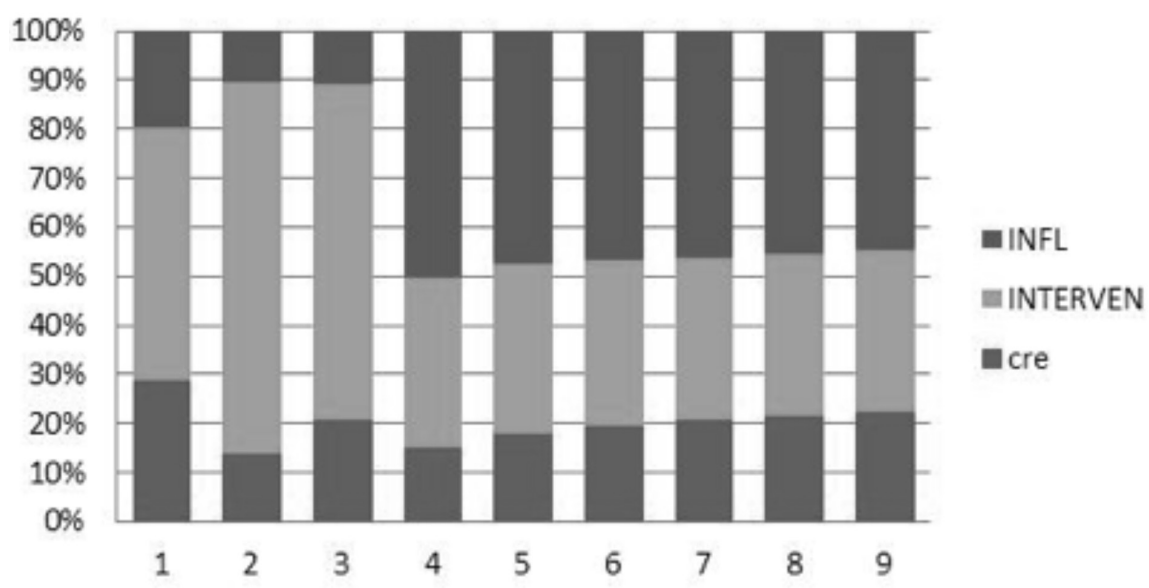

Descomposición INFL

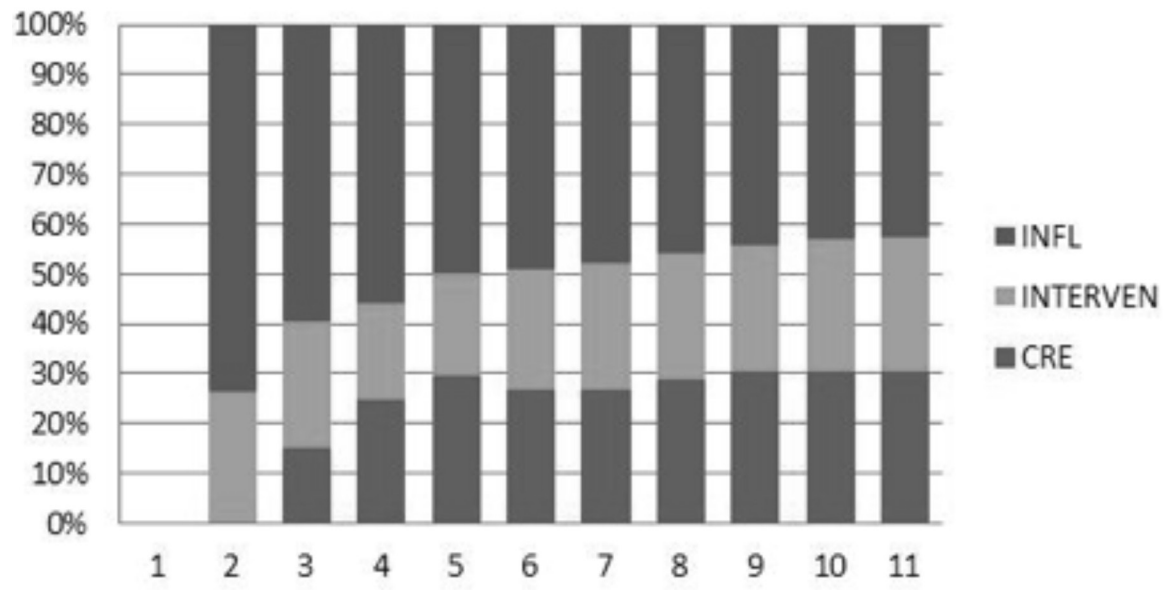

Fuente: EViews

En este punto se obtienen algunos resultados importantes en el modelo, pero existen algunos signos, como el del crecimiento dos periodos anteriores sobre el crecimiento, que dejan dudas de la utilización de este modelo. Debido a esta situación, se presenta el modelo 3, en el cual se aplica un filtro Hodrick y Prescott ${ }^{16}$ a la variable PIB, para ser

16 Es un método para extraer el componente secular o de una serie temporal. Fue propuesto en 1980 por Robert J. Hodrick y Edward C. Prescott. Descompone la serie observada en dos componentes: uno tendencial y otro cíclico. El ajuste de sensibilidad de la tendencia a las fluctuaciones a corto plazo es obtenido modificando un multiplicador $\lambda$. 
utilizada como aproximación a la tendencia del PIB, que es la más cercana a la idea que tienen los codirectores del Banco de la República para establecer la tasa de intervención (Hernández y Tolosa, 2009, p. 93). Al aplicar a este el filtro Hodrick y Prescott con el fin de realizar una aproximación al PIB potencial, presenta los resultados incluidos en el anexo 5, los cuales revelan un mecanismo de ajuste de la variable de intervención de un $99,99 \%$.

Ahora bien, al considerar la matriz de cointegración, no se obtienen acordes con los referentes teóricos planteados, pues la varianza explicada de la variable intervención solo queda explicada por ella y por la inflación.

Figura 11. Descomposición de la varianza con filtro Hodrick y Prescott

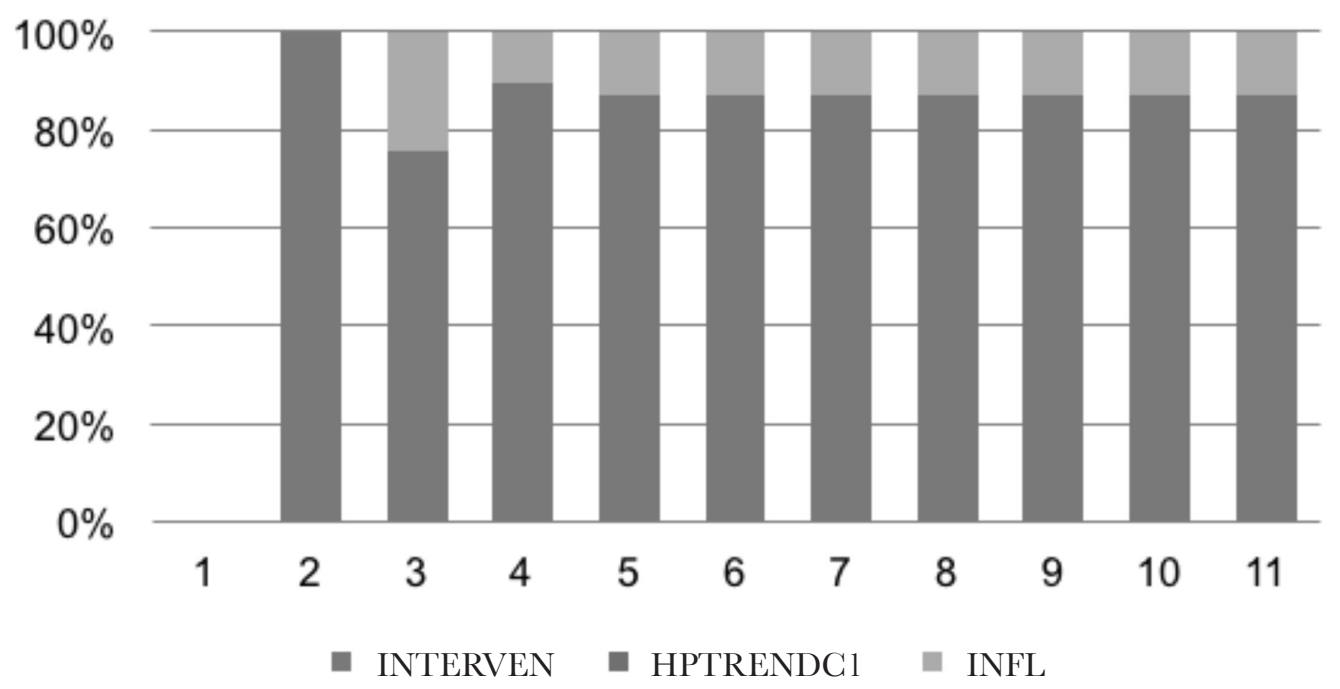

Fuente: EViews

Finalmente, al aplicar el Test de Cointegración de Johansen se obtiene que no existe una matriz de cointegración, por lo que se puede suponer que el modelo está correctamente especificado. Sin embargo, dados los resultados de la matriz de covarianza, se estimó un nuevo modelo que incluya las dos variables, obteniendo los resultados más adecuados; pero la variable con el filtro resultó no ser significativa. Por esta razón, el modelo con el cual se encontraron los resultados que describen mejor la relación entre variables planteada por los referentes teóricos fue el primero, el VAR, reseñado anteriormente. 


\section{Conclusiones}

Desde el punto de vista más personal, se ha encontrado relativamente poco material en el caso colombiano. En el Banco de la República, por ejemplo, existen pocos artículos acerca de la regla de Taylor. El primero de ellos acerca de la tasa de cambio de Latinoamérica y otro para el caso colombiano, que relaciona la política monetaria con la estabilidad financiera. Es por ello que este artículo propone una aproximación a la regla de Taylor con dos características importantes: la primera de ellas, la evaluación para un periodo de análisis que permite incorporar, por ejemplo, las ya citadas crisis. En segundo lugar, a partir de la aproximación de los datos y de modelos teóricos se escoge la metodología VAR, propia de este tipo de estudios.

Como fue expresado, como resultado de la investigación se encuentra que las políticas monetarias aplicadas en el periodo 1990- 2010 y en adelante responden correctamente a una serie de lineamientos puntuales del Banco Mundial respecto a cómo desarrollar el papel de autoridad monetaria en un país, el cual es considerado como un deber ser. Como contraste, las mencionadas políticas no responden a una identidad o a una serie de estudios que demuestren y justifiquen un progreso de dichas políticas, lo que se refleja en los cambios aplicados a un estado inicial de la autoridad monetaria no adaptable de un momento a otro de la situación internacional.

Adicionalmente, cabe anotar que eso sucede con la mayoría de las instituciones y de los marcos judiciales que las rigen, en los que, al tener un obstáculo identificado, se desarrolló el proceso por parte de los interesados para modificar y ajustar las reglas a las necesidades del actual contexto, por ejemplo, reformar la Constitución para permitir la reelección presidencial.

Por tal motivo, este tipo de conductas, las cuales han sido llamadas la actualización de la carta, generan desequilibrios en el sistema de contrapesos entre las instituciones, donde, y retomando el ejemplo anterior, la independencia del Banco de la República puede sesgarse debido a que el presidente escoge dos de los codirectores del Banco cada cuatro años - su cupo es prorrogable dos veces y pueden durar hasta doce años- más el ministro de Hacienda.

De la estilización de la política monetaria en Colombia se encontraron como principales características las siguientes:

- Todas las políticas monetarias aplicadas corresponden a una serie de caminos que buscan aumentar el crecimiento económico para generar desarrollo, el cual se considera que no es la manera fundamental de conseguirlo. Esto no responde a lo impuesto por la Ley 31 de 1992. Se presentan resultados menores conseguidos por otras funciones que pasan a ser secundarias en las actividades del Banco de la República. 
- Por otro lado, se considera que la autonomía constitucionalmente imputada a la junta directiva del Banco de la República como autoridad monetaria, cambiaria y crediticia no es absoluta, sino relativa, en el sentido de que debe ejercerse dentro de los términos de la Constitución y de la ley, dado que en ocasiones se limita a cumplir con lo correspondiente a sus funciones, pero su capacidad de previsión no es considerada como suficiente puesto que se buscan más resultados puntuales justificables ante las autoridades de control, que puedan cuestionar sus gastos, tales como las compras dadas de dólares y las pérdidas en las que se incurrió.

- Por otro lado, el gobierno desarrolló disminuciones de la deuda, pasando del 62,2\% de la deuda interna nacional en 1991 al 26,2\% en 1992 y al 9,6\% en 1995 debido al comienzo de nuevas fuentes de financiación que terminaron utilizándose, contribuyendo a disminuciones de intereses internos antes de la crisis de 1998 y facilitando la posibilidad de acceso a nuevos créditos para los ciudadanos.

- Después de la aplicación de la nueva Constitución, los ingresos corrientes de la nación aumentaron significativamente $(60 \%)$ debido a las facultades otorgadas al presidente, generando cualquier tipo de incentivos que en ocasiones tenían fundamentos políticos, como el otorgado a los cafeteros en 1997 previo a la crisis de 1998. Esta situación desarrolló apoyos focalizados a pequeños grupos productivos del país, con significativos montos de dinero, y que se consideran no justificables de acuerdo con el número de empleos directos generados. Más adelante se desmontó y decidió otorgarse apoyos como se dan actualmente, por ejemplo, comprar sacos de café a un precio mayor que el del mercado.

- Dentro de los cambios provocados por la Constitución de 1991, el proceso de comunicación y rendición de cuentas ha sido un salto a la modernización de las comunicaciones de las instituciones en un país donde estas son mediáticas. Dichas comunicaciones suscitaron fuertes decisiones en las expectativas de los agentes, donde podría decirse que las políticas monetarias aplicadas en el periodo 1990-2010 fueron mucho más impactantes que las originadas con la anterior Constitución.

- También cabe mencionar que cuando existe una coyuntura o un evento catalogado de crisis cuyos orígenes sean necesariamente dados en el sistema financiero o que de alguna manera estén relacionados con estos, se produce un patrón en el cual se socializan las pérdidas del sistema financiero con el fin de mantenerlo solvente, justificado por parte de la autoridad monetaria en la necesidad de mantener a flote muchas de las inversiones hechas por los bancos y constituirles en solventes, como sucedió con la crisis de 1998 y la implementación "temporal" de un impuesto, como lo es el 4 por mil, que inició como dos por mil y hoy se tramita para que sea la fuente del $60 \%$ de los subsidios otorgados a los campesinos colombianos. 
ISSN: 0124-3551 / Año 16, No 25 / julio-diciembre / pp. 71-122

De la caracterización del comportamiento del crecimiento económico de Colombia se pueden extraer las siguientes conclusiones:

- Con la apertura económica, las limitantes en la importación de productos se eliminaron y, como resultado de esto, la competitividad que gozan otros países se reflejó en el aumento de estas, el consumo interno y la quiebra de muchas empresas colombianas a las cuales les quedó complicado competir contra los orígenes de las multinacionales. Esto ocasionó, además, y como aspecto positivo, la importación de maquinaria y equipo, técnicas e insumos varios que generaron en el país aumentos de la productividad y, como resultado, el crecimiento económico nacional.

- Las políticas aplicadas en la crisis de 1998 desarrollaron un nuevo paradigma que se introdujo el país. Se dice paradigma porque el tipo de cambio era totalmente nuevo y porque nunca se había dejado que el precio de la TRM se calculara por medio del mercado. Siendo así, llegado el año 2000, y con ligeros aumentos de confianza en el país por los diálogos de paz, el crecimiento económico comenzó su etapa de desarrollo con fines de auge, de los cuales se obtendría el mayor resultado, y el gobierno Uribe presentaría el mayor crecimiento en 50 años: 6,9\%.

- A finales de los años noventa, el petróleo y sus hallazgos masivos aseguraron una oleada de capitales que revaluaron la tasa de cambio; gracias al desbordado gasto público, terminaron de crearse una serie de profundos desequilibrios macroeconómicos que se convirtieron en las burbujas en los mercados accionarios y de finca raíz.

- Se considera que las políticas anticíclicas y la armonización de las políticas fiscal y monetaria presentaron un avance que las constituyó de verdad en instrumentos aplicables a coyunturas de corto plazo en el país. Por ejemplo, en 2001 estos instrumentos se aplicaron para visualizar y proyectar un horizonte de crecimiento significativo en el que se obtuvieran una serie de recursos con los cuales cumplir con los objetivos planteados por Estados Unidos para asegurar la prevalencia de los recursos del Plan Colombia. Dichos objetivos giraban en torno a aumentos del crecimiento económico sostenibles, desarrollo de políticas monetarias de largo plazo, el aseguramiento de que en el país se aplicaban buenas prácticas y, entre otras, la seguridad de que el narcoterrorismo estaba condenado a su fin.

Para terminar, respecto a la relación y evidencia empírica que se estimó en torno a la política monetaria y el crecimiento económico de 1990 a 2010, se afirma lo siguiente:

- El país desarrolló avances retardados en materia de contabilización de indicadores que aumentarían la precisión de las estimaciones de agregados macroeconómicos que fortalecieran los objetivos de las políticas y sus resultados, haciéndolos de mayor 
alcance respecto a periodos anteriores a 1993, cuando el cálculo del PIB trimestral para Colombia no existía.

- Los resultados del modelo muestran que la oferta monetaria es endógena, cumpliendo con lo que se encuentra en la hipótesis, de manera que es posible concluir que bajo la evidencia empírica obtenida por el modelo VAR existe una causalidad implícita en las decisiones de política monetaria y el uso de los instrumentos por parte de la autoridad, basados en lo ocurrido en el periodo 1990- 2010 para Colombia.

- Los resultados también muestran que la explicación provista por el VAR en el segundo caso revela un ajuste del $99 \%$, lo que se considera apropiado para este tipo de trabajos, con lo cual más que la metodología en sí misma, puede realizarse una aproximación seria a dicha regla. 


\section{Referencias}

Álvarez de Toledo, P., Crespo, A. Núñez, F. y Usabiaga, C. (2006). Introducción de elementos autorregresivos en modelos de dinámica de sistemas. Revista de Dinámica de Sistemas, 2(1), 37-66.

Arango, L. E., González, A., León, J. J. y Melo, L. F. (2006). Cambios en la tasa de intervención y su efecto en la estructura a plazo de Colombia. Borradores de Economía, 424.

Arestis, P., \& Sawyer, M. (2003). The nature and role of monetary policy when money Is endogenous (n.o 374). The Levy Economics Institute Working Paper. Recuperado de http://hdl. handle.net/10419/31503

Argov, E., Epstein, N., Karam, P., Laxton, D., \& Rose, D. (2007, julio). Endogenous monetary policy credibility in a small macro model of Israel (n.o 07/207). IMF Working Paper. Recuperado de https://www.imf.org/external/pubs/ft/wp/2007/wp07207.pdf

Atehortúa, S., López, M. y Mesa, R. J. (201 1). Crecimiento económico colombiano en 2011, "disparado" a pesar de las turbulencias externas: análisis de la coyuntura y perspectivas en 2012. Perfil de Coyuntura Económica, 18, 7-26. Recuperado de http:// www.redalyc.org/articulo.oa?id=86125453001

Banco Central Europeo. (2008). El tipo de interés oficial del BCEy la regla de Taylor. Recuperado de http://www.economiaandaluza.es/sites/default/files/cap472.pdf

Barón, J. D. y Meisel, A. (2009). A historical Analisis of Central Bank Independence in Latin America: The Colombian Experience, 1923-2008. Borradores de Economía, 573. Recuperado de http://www.banrep.gov.co/docum/ftp/borra573.pdf

Bernal Nisperuza, G. L. y Táutiva Pradere, J. (2011). Datos en tiempo real: Una aplicación a la regla de Taylor en Colombia. Revista de Economía Institucional, 13(24), 373394. Recuperado de http://www.economiainstitucional.com/pdf/no24/gbernal24. pdf

Betancourt, Y. R. y Vargas, H. (2008). Encajes bancarios y las estrategias de inflación objetivo. Borradores de Economía, 533. Recuperado de http://www.banrep.gov.co/docum/ftp/borra533.pdf

Bustamante, C. (2011). Política monetaria contracíclica y encaje bancario. Borradores de Economía, 646. 
Clarida, R., Galí, J., \& Gerther, M. (1999). The science of monetary policy: A new Keynesian Perspective. International Macroeconomics. Fournal of Economic Literature, 37(2), 1661-1707.

Clavijo, S. (2000). Banca central y coordinación macroeconómica: El caso de Colombia. Borradores de Economía, 164.

- (2003). Crecimiento, productividad y la 'nueva economía': Implicaciones para Colombia. Borradores de Economía, 228.

. (2003). Politica monetaria y cambiaria en Colombia: Progresos y desafios (1991-2002).

Recuperado de http://www.banrep.gov.co/docum/ftp/borra201.pdf

- (2000). Reflexiones sobre política monetaria e "inflación objetivo" en Colombia. Borradores de Economía, 141.

Cuevas, H. (1986). Dinámica del proceso de industrialización en Colombia. Revista Economía Colombiana.

García, J. G. (2002). Liberalización, cambio estructural y crecimiento económico en Colombia. Cuadernos de Economía, 36, 189-244.

Cushman, D., \& Zha, T. (1997). Identifying monetary policity in a small open economy under flexible exchange rates. Fournal of Monetary Economics, 39(3), 433-448.

Davig, T., \& Leeper M. E. (2006). Endogenous monetary policy regime change. Recuperado de http://www.nber.org/chapters/c7039.pdf

De Gregorio, J. (2003). Dinero e inflación: ¿En qué estamos? (n.o 201). Banco Central de Chile. Documento de trabajo.

Echavarría, J. J. et al. (2007). El proceso colombiano de desindustrialización. Economía colombiana del siglo XX, un análisis cuantitativo. Bogotá: Fondo de Cultura Económica.

Fernández, A. (2005). Política monetaria: Enfoques alternativos (tomo II). España: AC Editorial.

Fernández, A., Rodríguez, L., Parejo, J. A., Calvo, A. y Galindo, M. Á. (2003). Política monetaria: Fundamentos y estrategias (tomo I). España: AC Editorial.

Foldén, M. (2000). Endogenous monetary policy and the business cycle. European Economic Review 44, 1409-1429. Recuperado de http://goo.gl/bDw59t 
ISSN: 0124-3551 / Año 16, No 25 / julio-diciembre / pp. 71-122

Forni, P., Kreimer, P., \& Thomas, H. (s. f.). Estrategia de investigación III. La adopción de perspectivas metodológicas. Material elaborado para el Seminario de Tesis del Doctorado de FLACSO-Argentina.

Galí, J. (1998). La política monetaria europea y sus posibles repercusiones sobre la economía española. N. Y.: New York University.

Galindo, L. M. y Guerrero, C. (2003). La regla de Taylor para México: Un análisis econométrico. Investigación económica, LXII(246), 149-167. Recuperado de https:// goo.gl/yueC3G

García, J. G. (1999). El cambio del patrón de especialización en el plan de desarrollo. Cuadernos de Economía, 30, 85-102. Recuperado de http://www.bdigital.unal.edu. co/16534/1/11431-73538-1-PB.pdf

. (1995). Fundamentos teóricos de la estrategia de internacionalización en el Plan de Desarrollo 1994-1998. Cuadernos de Economía, 22, 204-220.

- (2002). Liberalización, cambio estructural y crecimiento económico en Colombia. Cuadernos de Economía, 21(36), 188-244.

Gaviria, M. A. (2007). Apuntes de teoría y política monetaria. Pereira: Eumed.net. Recuperado de http://www.cyta.com.ar/biblioteca/bddoc/bdlibros/teoria_monetaria.pdf

Giraldo, A. F. (2008). Aversión a la inflación y la regla de Taylor en Colombia. 19942005. Cuadernos de Economía, 27(49), 225-257. Recuperado de http://goo.gl/fxQ17w

Gómez, J. G. (2006). La politica monetaria en Colombia. Recuperado de http://www.banrep. gov.co/docum/ftp/borra394.pdf

Gómez, K. y Gallón, S. (2002). El impacto de la corrupción sobre el crecimiento económico colombiano, 1990-1999. Lecturas de Economía, 57, 51-85. Recuperado de http://goo.gl/DhLyZP

Gómez, W. y Posada, C. E. (2002). Crecimiento económico y gasto público: Un modelo para el caso colombiano. Borradores de Economía, 218.

Gujarati, D., \& Porter, D. C. (2011). Econometría (5.a ed.). México: McGraw Hill.

Hernández, A. y Tolosa, J. (2001). La política monetaria en Colombia en la segunda mitad de los años noventa. Borradores de Economía, 172. 
Kalmanovitz, S. (2004). Recesión y recuperación de la economía colombiana. Nueva Sociedad, 192. Recuperado de http://nuso.org/media/articles/downloads/3211_1. pdf

Lora, E. (2009). Técnicas de medición económica. Metodología y aplicaciones en Colombia (4.a ed.) Bogotá: Alfaomega.

Mankiw, G. N. (2006). Macroeconomía (6.a ed.). España: Antoni Bosch Editor.

Mánteyde, G. (2000). Hyman P. Minsky en el pensamiento económico del siglo XX. Comercio Exterior, 50(12), 1069-1077. Recuperado de http://revistas.bancomext.gob. $\mathrm{mx} / \mathrm{rce} / \mathrm{magazines} / 41 / 6 / \mathrm{RGE} . \mathrm{pdf}$

Melo, L. F. y Riascos, Á. (2004). Sobre los efectos de la política monetaria en Colombia. Ensayos sobre Politica Económica, 45. Recuperado de http://www.banrep.org/docum/ ftp/borra281.pdf

Minsky, H. P. (1990). Endogeneity of Money. Hyman P. Minsky Archive. Paper 430. Recuperado de http://digitalcommons.bard.edu/hm_archive/430

Misas, M. A. y Posada, C. E. (2000). Crecimiento y ciclos económicos en Colombia en el siglo XX: el aporte de un VAR estructural. Borradores de Economía, 155. Recuperado de http://www.banrep.gov.co/docum/ftp/borra155.pdf

Mishkin, F. S. (2000). De metas monetarias a metas de inflación: Lecciones de los paises industrializados. Recuperado de http://goo.gl/JQ9P7z

(1999). International experiences with different monetary policy regimes. Journal of Monetary Economics, 43(3), 579-605.

. (1995). Symposium on the Monetary Transmission Mechanism. The Journal of Economic Perspectives, 9(4), 3-10.

Ochoa, A. y Peña, P. (2002). Moneda y banca en Colombia: Análisis historiográfico 1863-1923. Bogotá: Universidad Nacional de Colombia.

Ojeda, J., Montes, E. y Rubio, O. (2003). Deuda externa, inversión y crecimiento en Colombia, 1970-2002. Borradores de Economía, 272. Recuperado de http://www.banrep.gov.co/docum/ftp/borra272.pdf

Ortiz, G. H., Uribe, J. I. y Vivas, H. (2009). Transformación industrial, autonomía tecnológica y crecimiento económico: Colombia 1925-2005. Archivos de Economía. Documento 352. Recuperado de https: / / colaboracion.dnp.gov.co/CDT/Estudios\%20 Econmicos/352.pdf 
ISSN: 0124-3551 / Año 16, No 25 / julio-diciembre / pp. 71-122

Ortiz, C. H. y Vásquez, L. M. (2007). Aprendizaje manufacturero, dependencia tecnológica y crecimiento económico: El caso colombiano. Sociedad y Economía, 12, 1027. Recuperado de http://goo.gl/OgOqPH

Paredes, E., Santana, L., Sánchez, A. y Torres, F. (2013). Estimación de la tasa de interés real neutral en la República Dominicana (n.o 2013-02). BCRD Documento de trabajo. Recuperado de http://goo.gl/g3dNrL

Perrotini, I. (2008). El nuevo paradigma monetario. Economía UNAM, 4(11), 64-82. Recuperado de http://goo.gl/YjPTLI

Posada, G. E. y Rojas, A. (2008). El crecimiento económico colombiano: datos nuevos y modelos viejos para interpretar el periodo 1925-2000. Borradores de Economía, 480.

Posada, C. E. (2000). Señoreaje, impuesto inflacionario y utilidades (brutas) del emisor: definiciones y medidas del caso colombiano reciente. Reportes del Emisor, 15. Recuperado de http://www.banrep.gov.co/docum/Lectura_finanzas/pdf/15_0.pdf

Ricaurte Herrera, C., Lugo, T., \& Hidalgo, A. (2008). Historia de la cooperación monetaria y financiera internacional y su importancia en el desarrollo del mercado financiero internacional. FORO. Revista de Derecho, 10, 67-84.

Rodríguez, C., Padrón, D. y Olivera, A. (2004). La endogeneidad de la oferta monetaria: Teoría y evidencia empírica para la economía española. Revista Asturiana de Economía - RAE, 29, 91-110. Recuperado de http://www.revistaasturianadeeconomia.org/raepdf/29/P91-110.pdf

Rodríguez, J. I., Perilla, J. R. y Reyes Peña, J. D. (2004, julio). Cálculo del PIB potencial en Colombia. 1970-2003. Archivos de Economía. Documento 261. Recuperado de https://colaboracion.dnp.gov.co/CDT/Estudios\%20Econmicos/261.pdf

Rosende, F. (2002). La nueva síntesis keynesiana: análisis e implicancias de política monetaria. Cuadernos de Economía, 39(117), 203-233. Recuperado de http://goo.gl/ $\mathrm{MgC8Wb}$

Sánchez, F., Fernández, A. y Armenta, A. (2005). Historia monetaria de Colombia en el siglo XX: Grandes tendencias y episodios relevantes. Ensayos sobre historia económica de Colombia en el siglo XX. Documento CEDE 2005- 30. Recuperado de http://economia.uniandes.edu.co/publicaciones/d2005-30.pdf

Sims, C. (2006). Macroeconomics and reality. Econometrica, 48(1) (enero de 1980), 1-48. 
Steiner, R. (2009). La política económica contra-cíclica: alternativas, resultados y recomendaciones. Debates de Coyuntura Económica, 77. Recuperado de http://goo.gl/ wL3RNz

Taylor, J. B. (1993). Discretion versus policy rules in practice. Carnegie-Rochester Conference Series on Public Policy, 39, 195-214. Recuperado de http://web.stanford.edu/ johntayl/ Papers/Discretion.PDF

. (2000). Uso de reglas de política monetaria en economías de mercado emergentes.

Recuperado de http://goo.gl/SMRXMb

Uribe, J. D. (1994). Inflación y crecimiento económico 1951-1992. Borradores Semanales de Economía, 1. Recuperado de http://www.banrep.gov.co/docum/ftp/borra001.pdf

Urrutia, M. (2002). Una visión alternativa: La política monetaria y cambiaria en la última década. Borradores de Economía, 207. Recuperado de http://www.banrep.gov. co/docum/ftp/borra207.pdf

Valdés, R. (1998). Efectos de la política monetaria en Chile. Cuadernos de Economía, 35(104), 97-125. Recuperado de http://economia.uc.cl/docs/104valda.pdf

Villar, L. (2001). Reglas versus discrecionalidad en las políticas fiscal, monetaria y cambiaria: Un problema de economía política y credibilidad. Recuperado de http://www.banrep.gov.co/ docum/Lectura_finanzas/pdf/cepalsemnifiscal.pdf

Zuluaga, Ó. I. (2009). La política fiscal en medio de la crisis y sus perspectivas. Debates de Coyuntura Económica, 77. 


\section{Anexos}

\section{Anexo 1. Modelo Vectores Autorregresivos VAR}

Vector Autoregression Estimates

Date: 11/10/13 - Time: 15:10

Sample (adjusted): 1993Q1 2012Q4

Included observations: 78 after adjustments

Standard errors in () \& t-statistics in []

CRE(-1)

\begin{tabular}{|c|c|c|}
\hline \multicolumn{1}{|c|}{ GRE } & INTERVEN & \multicolumn{1}{c|}{ INFL } \\
\hline-0.138798 & 0.190481 & -0.034385 \\
\hline$(0.13526)$ & $(0.05318)$ & $(0.02551)$ \\
\hline$[-1.02618]$ & {$[3.58177]$} & {$[-1.34787]$} \\
\hline 0.175912 & 0.176496 & 0.030366 \\
\hline
\end{tabular}

CRE(-2)

$(0.12901)$

(0.05072)

(0.02433)

INTERVEN(-1)

[ 1.36358$]$

[3.47962]

[ 1.24802$]$

$-0.134319$

1.449448

0.027802

(0.21046)

(0.08275)

(0.03969)

[-0.63820]

[ 17.5159]

[0.70038]

0.316648

$-0.533249$

0.018374

INTERVEN(-2)

(0.20241)

(0.07958)

(0.03818)

[ 1.56441$]$

[-6.70054]

[0.48131]

$\operatorname{INFL}(-1)$

$-0.902662$

0.197439

0.087550

$(0.64552)$

$(0.25381)$

(0.12175)

[-1.39834]

[0.77791]

[0.71910]

$-2.204613$

0.360869

$-0.640122$

INFL(-2)

(0.65532)

(0.25766)

(0.12360)

[-3.36419]

[ 1.40057$]$

[-5.17910]

C

0.013049

$-0.002189$

0.003700

(0.00429)

(0.00169)

(0.00081)

[3.04401]

[-1.29858]

[4.57562]

R-squared

Adj. R-squared

Sum sq. Resids

0.468703

0.996966

0.637354

0.423804

0.996709

0.606708

S.E. equation

0.038657

0.005976

0.001375

0.023334

0.009174

0.004401

F-statistic

Log likelihood

Akaike AIC

Schwarz SC

Mean dependent

10.43919

3887.956

20.79723

186.1029

258.9148

316.2142

$-4.592383$

$-6.459354$

$-7.928570$

$-4.380883$

$-6.247855$

$-7.717071$

S.D. dependent

0.024104

0.169377

0.007460

0.030740

0.159928

0.007017 
Determinant resid covariance (dof adj.)

Determinant resid covariance

Log likelihood

Akaike information criterion

Schwarz criterion
$6.24 \mathrm{E}-13$

4.71E-13

774.9815

$-19.33286$

$-18.69836$

\section{Anexo 2. Descomposición de la varianza}

\begin{tabular}{|c|c|c|c|c|}
\hline \multicolumn{5}{|c|}{ Variance Decomposition of GRE: } \\
\hline Period & S.E. & CRE & INTERVEN & INFL \\
\hline 1 & 0.023334 & 72.80034 & 0.328152 & 26.87151 \\
\hline 2 & 0.024217 & 68.89082 & 0.847699 & 30.26149 \\
\hline 3 & 0.025548 & 64.34342 & 0.913123 & 34.74346 \\
\hline 4 & 0.025658 & 63.79355 & 1.138324 & 35.06812 \\
\hline 5 & 0.026116 & 61.58228 & 1.611919 & 36.80580 \\
\hline 6 & 0.026148 & 61.44078 & 1.818350 & 36.74087 \\
\hline 7 & 0.026268 & 61.25308 & 1.917447 & 36.82947 \\
\hline 8 & 0.026340 & 61.16364 & 2.100832 & 36.73553 \\
\hline 9 & 0.026425 & 60.86368 & 2.288809 & 36.84751 \\
\hline 10 & 0.026455 & 60.83154 & 2.402996 & 36.76546 \\
\hline \multicolumn{5}{|c|}{ Variance Decomposition of INTERVEN: } \\
\hline Period & S.E. & GRE & INTERVEN & INFL \\
\hline 1 & 0.009174 & 0.000000 & 100.0000 & 0.000000 \\
\hline 2 & 0.016819 & 5.083928 & 91.39107 & 3.525001 \\
\hline 3 & 0.024527 & 13.97826 & 75.74256 & 10.27918 \\
\hline 4 & 0.030173 & 20.78201 & 68.47292 & 10.74507 \\
\hline 5 & 0.034406 & 27.10481 & 63.72891 & 9.166284 \\
\hline 6 & 0.037845 & 31.38812 & 60.37112 & 8.240756 \\
\hline 7 & 0.040687 & 33.72555 & 58.19452 & 8.079930 \\
\hline 8 & 0.042981 & 35.17113 & 56.87462 & 7.954246 \\
\hline 9 & 0.044878 & 36.33922 & 55.97079 & 7.689995 \\
\hline 10 & 0.046523 & 37.23770 & 55.26485 & 7.497442 \\
\hline \multicolumn{5}{|c|}{ Variance Decomposition of INFL: } \\
\hline Period & S.E. & GRE & INTERVEN & INFL \\
\hline 1 & 0.004401 & 0.000000 & 3.449317 & 96.55068 \\
\hline 2 & 0.004470 & 2.345899 & 4.039087 & 93.61501 \\
\hline 3 & 0.005005 & 4.087106 & 3.238520 & 92.67437 \\
\hline
\end{tabular}




\begin{tabular}{|c|c|c|c|c|}
\hline Period & S.E. & GRE & INTERVEN & \multicolumn{1}{c|}{ INFL } \\
\hline 4 & 0.005056 & 5.339050 & 3.738951 & 90.92200 \\
\hline 5 & 0.005273 & 4.977388 & 4.472367 & 90.55024 \\
\hline 6 & 0.005287 & 5.029608 & 4.845524 & 90.12487 \\
\hline 7 & 0.005341 & 5.592434 & 4.894045 & 89.51352 \\
\hline 8 & 0.005363 & 6.089790 & 5.124597 & 88.78561 \\
\hline 9 & 0.005398 & 6.173516 & 5.418202 & 88.40828 \\
\hline 10 & 0.005409 & 6.292323 & 5.624906 & 88.08277 \\
\hline
\end{tabular}

\section{Anexo 3. Test de Cointegración}

Date: 12/10/13 - Time: 11:50

Sample (adjusted): 1993Q1 2012Q4

Included observations: 77 after adjustments

Trend assumption: Linear deterministic trend

Series: CRE INTERVEN INFL

Lags interval (in first differences): 1 to 2

\section{Unrestricted Gointegration Rank Test (Trace)}

\begin{tabular}{|c|c|c|c|c|}
\hline $\begin{array}{l}\text { Hypothesized } \\
\text { No. of CE(s) }\end{array}$ & Eigenvalue & $\begin{array}{l}\text { Trace } \\
\text { Statistic }\end{array}$ & $\begin{array}{c}0.05 \\
\text { Critical Value }\end{array}$ & Prob.** \\
\hline None * & 0.545055 & 101.6804 & 29.79707 & 0.0000 \\
\hline At most $1 *$ & 0.284141 & 41.03679 & 15.49471 & 0.0000 \\
\hline At most $2 *$ & 0.180182 & 15.29782 & 3.841466 & 0.0001 \\
\hline
\end{tabular}

\section{Unrestricted Gointegration Rank Test (Maximum Eigenvalue)}

\begin{tabular}{|l|c|c|c|c|}
\hline $\begin{array}{c}\text { Hypothesized } \\
\text { No. of CE(s) }\end{array}$ & Eigenvalue & Max-Eigen & $\begin{array}{c}0.05 \\
\text { Critical Value }\end{array}$ & Prob.** \\
\hline None * & 0.545055 & 60.64356 & 21.13162 & 0.0000 \\
\hline At most $1 *$ & 0.284141 & 25.73897 & 14.26460 & 0.0005 \\
\hline At most $2 *$ & 0.180182 & 15.29782 & 3.841466 & 0.0001 \\
\hline
\end{tabular}

Max-eigenvalue test indicates 3 cointegrating eqn(s) at the 0.05 level

* denotes rejection of the hypothesis at the 0.05 level

**MacKinnon-Haug-Michelis (1999) p-values

\section{Unrestricted Cointegrating Coefficients (normalized by $\left.b^{\prime} * \mathrm{~S} 11 * \mathrm{~b}=\mathrm{I}\right)$ :}

\begin{tabular}{|c|c|c|}
\hline CRE & INTERVEN & INFL \\
\hline 52.94271 & -18.73421 & 351.0492 \\
\hline
\end{tabular}




\begin{tabular}{|c|c|c|}
\hline CRE & INTERVEN & \multicolumn{1}{|c|}{ INFL } \\
\hline 76.02153 & 2.744967 & -389.1312 \\
\hline 12.30002 & 4.731952 & 34.70751 \\
\hline
\end{tabular}

\begin{tabular}{l|l|l|l|}
\hline Unrestricted Adjustment Coefficients $($ alpha): \\
\hline D(CRE) & -0.016208 & -0.003067 & -0.006926 \\
\hline D(INTERVEN) & 0.004614 & 0.003046 & -0.002611 \\
\hline D(INFL) & -0.003023 & 0.001776 & -0.000520 \\
\hline
\end{tabular}

\begin{tabular}{|c|c|c|}
\hline \multicolumn{2}{|l|}{ 1 Cointegrating Equation(s): } & \multicolumn{2}{c|}{ Log likelihood } \\
\hline \multicolumn{2}{|c|}{ Normalized cointegrating coefficients (standard error in parent } \\
\hline CRE & INTERVEN & INFL \\
\hline 1.000000 & -0.353858 & 6.630738 \\
\hline
\end{tabular}

Adjustment coefficients (standard error in parentheses)

\begin{tabular}{|l|r|}
\hline $\mathrm{D}(\mathrm{CRE})$ & -0.858071 \\
\hline & $(0.14515)$ \\
\hline $\mathrm{D}($ INTERVEN $)$ & 0.244277 \\
\hline & $(0.05988)$ \\
\hline $\mathrm{D}(\mathrm{INFL})$ & -0.160024 \\
\hline & $(0.02866)$ \\
\hline
\end{tabular}

\begin{tabular}{|c|c|c|}
\hline \multicolumn{2}{|l|}{2 Cointegrating Equation(s): } & \multicolumn{1}{|c|}{ Log likelihood } \\
\hline Normalized cointegrating coefficients & standard error in parenth \\
\hline CRE & INTERVEN & INFL \\
\hline 1.000000 & 0.000000 & -4.030793 \\
\hline 0.000000 & & $(0.48696)$ \\
\hline
\end{tabular}

Adjustment coefficients (standard error in parentheses)

\begin{tabular}{|l|r|r|}
\hline $\mathrm{D}(\mathrm{CRE})$ & -1.091257 & 0.295216 \\
\hline $\mathrm{D}($ INTERVEN) & $(0.25166)$ & $(0.05144)$ \\
\hline $\mathrm{D}(\mathrm{INFL})$ & 0.475825 & -0.078079 \\
\hline & $(0.09911)$ & $(0.02026)$ \\
\hline & -0.025010 & 0.061501 \\
\hline
\end{tabular}




\section{Anexo 4. Segundo Modelo de Vector Autorregresivo}

Vector Autoregression Estimates

Date: 11/28/13 - Time: 09:49

Sample (adjusted): 1993Q1 2012Q4

Included observations: 78 after adjustments

Standard errors in () \& t-statistics in []

\begin{tabular}{|c|c|c|c|c|}
\hline & INTERVEN & GRE & HPTREND01 & INFL \\
\hline \multirow{3}{*}{ INTERVEN(-1) } & 1.408230 & -0.323091 & -0.000928 & 0.037556 \\
\hline & $(0.08774)$ & $(0.21527)$ & $(0.00040)$ & $(0.04018)$ \\
\hline & [ 16.0496] & {$[-1.50084]$} & {$[-2.31526]$} & [0.93469] \\
\hline \multirow{3}{*}{ INTERVEN(-2) } & -0.565884 & 0.186745 & 0.000556 & -0.021705 \\
\hline & $(0.08576)$ & $(0.21041)$ & $(0.00039)$ & $(0.03927)$ \\
\hline & [-6.59832] & [0.88752] & [ 1.41869$]$ & {$[-0.55266]$} \\
\hline \multirow{3}{*}{ CRE(-1) } & 0.151996 & -0.314478 & -0.001191 & -0.026678 \\
\hline & $(0.05969)$ & $(0.14644)$ & $(0.00027)$ & $(0.02733)$ \\
\hline & [2.54654] & {$[-2.14747]$} & [-4.36995] & [-0.97602] \\
\hline \multirow{3}{*}{ CRE(-2) } & 0.137011 & -0.000902 & -0.000786 & 0.029883 \\
\hline & $(0.05696)$ & $(0.13974)$ & $(0.00026)$ & $(0.02608)$ \\
\hline & [2.40553] & {$[-0.00646]$} & [-3.02232] & [ 1.14572] \\
\hline \multirow{3}{*}{ HPTREND01(-1) } & -1.247589 & -4.194196 & 1.974503 & -3.418493 \\
\hline & $(2.46129)$ & (6.03868) & $(0.01124)$ & $(1.12711)$ \\
\hline & {$[-0.50689]$} & {$[-0.69456]$} & [ 175.636] & [-3.03298] \\
\hline \multirow{3}{*}{ HPTREND01(-2) } & 1.830941 & 6.765398 & -0.971782 & 3.525858 \\
\hline & $(2.60492)$ & $(6.39107)$ & $(0.01190)$ & (1.19288) \\
\hline & [0.70288] & [ 1.05857$]$ & [-81.6759] & [2.95575] \\
\hline \multirow{3}{*}{ INFL(-1) } & 0.286595 & -0.470839 & 0.002121 & 0.008998 \\
\hline & $(0.26906)$ & $(0.66014)$ & $(0.00123)$ & $(0.12321)$ \\
\hline & [ 1.06516$]$ & {$[-0.71324]$} & [ 1.72555$]$ & [0.07303] \\
\hline \multirow{3}{*}{ INFL(-2) } & 0.421640 & -1.908273 & 0.001398 & -0.698558 \\
\hline & $(0.26506)$ & (0.65032) & $(0.00121)$ & $(0.12138)$ \\
\hline & [ 1.59071$]$ & {$[-2.93434]$} & [ 1.15450$]$ & {$[-5.75504]$} \\
\hline \multirow{3}{*}{ C } & -0.004207 & 0.003585 & $4.20 \mathrm{E}-05$ & 0.004723 \\
\hline & $(0.00237)$ & $(0.00582)$ & $(1.1 \mathrm{E}-05)$ & (0.00109) \\
\hline & {$[-1.77334]$} & [0.61597] & [ 3.87404] & [ 4.34793] \\
\hline R-squared & 0.997067 & 0.522061 & 0.999996 & 0.680514 \\
\hline Adj. R-squared & 0.996727 & 0.466648 & 0.999995 & 0.643472 \\
\hline Sum sq. resids & 0.005777 & 0.034774 & $1.21 \mathrm{E}-07$ & 0.001211 \\
\hline S.E. equation & 0.009150 & 0.022449 & $4.18 \mathrm{E}-05$ & 0.004190 \\
\hline F-statistic & 2931.749 & 9.421250 & 1941586. & 18.37148 \\
\hline Log likelihood & 260.2357 & 190.2307 & 680.5608 & 321.1560 \\
\hline
\end{tabular}




\begin{tabular}{|l|c|c|c|c|}
\hline & INTERVEN & GRE & HPTREND01 & \multicolumn{1}{c|}{ INFL } \\
\hline Akaike AIC & -6.441942 & -4.646940 & -17.21951 & -8.004001 \\
\hline Schwarz SC & -6.170014 & -4.375012 & -16.94758 & -7.732073 \\
\hline Mean dependent & 0.169377 & 0.024104 & 0.024354 & 0.007460 \\
\hline S.D. dependent & 0.159928 & 0.030740 & 0.018771 & 0.007017 \\
\hline Determinant resid covariance (dof adj.) & $6.54 \mathrm{E}-22$ & & \\
\hline Determinant resid covariance & $4.00 \mathrm{E}-22$ & & \\
\hline Log likelihood & 1478.812 & & \\
\hline Akaike information criterion & -36.99518 & & \\
\hline Schwarz criterion & -35.90747 & &
\end{tabular}

\section{Anexo 5. Análisis impulso respuesta segundo VAR con filtro Hodrick y Prescott}

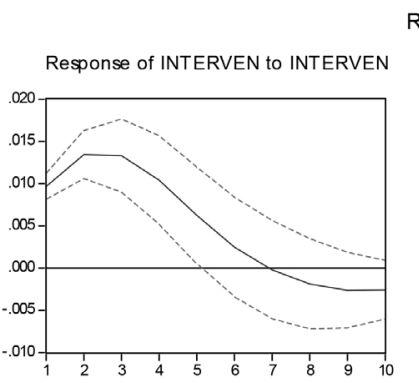

Response to CholeskyOne S.D. Innovations \pm 2 S.E.
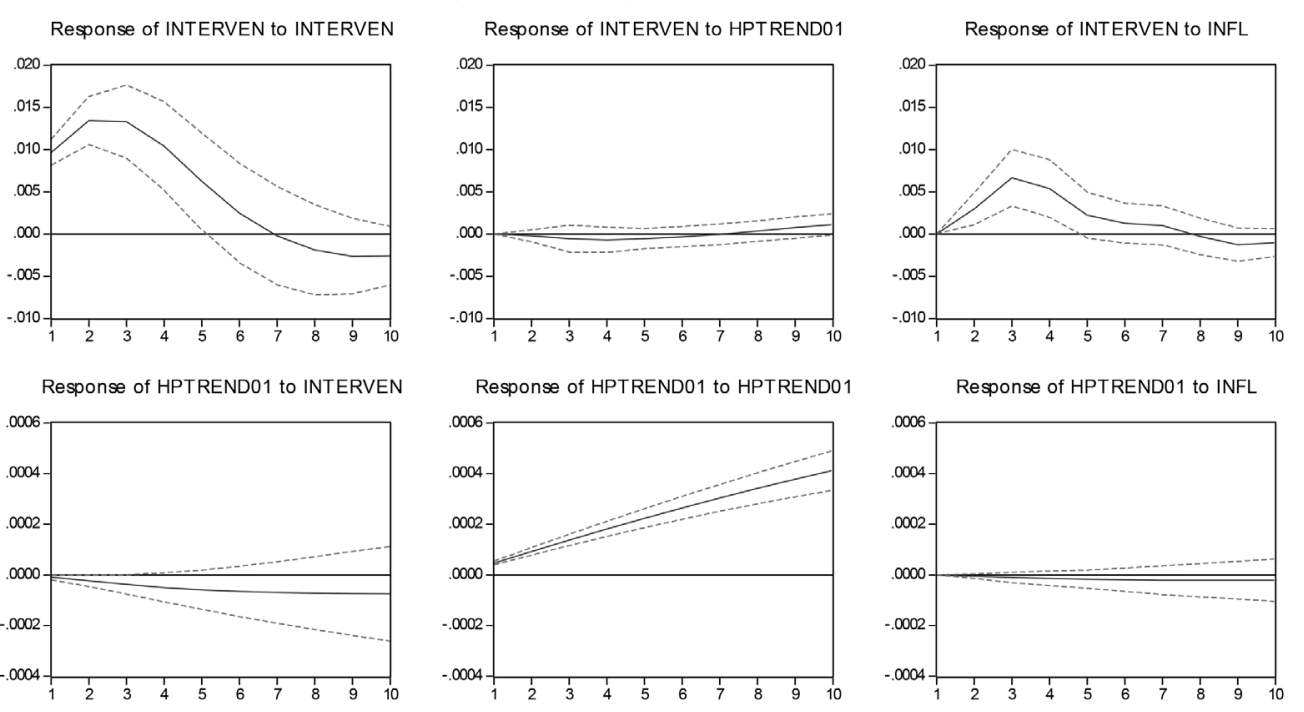

Response of INFL to INTERVEN
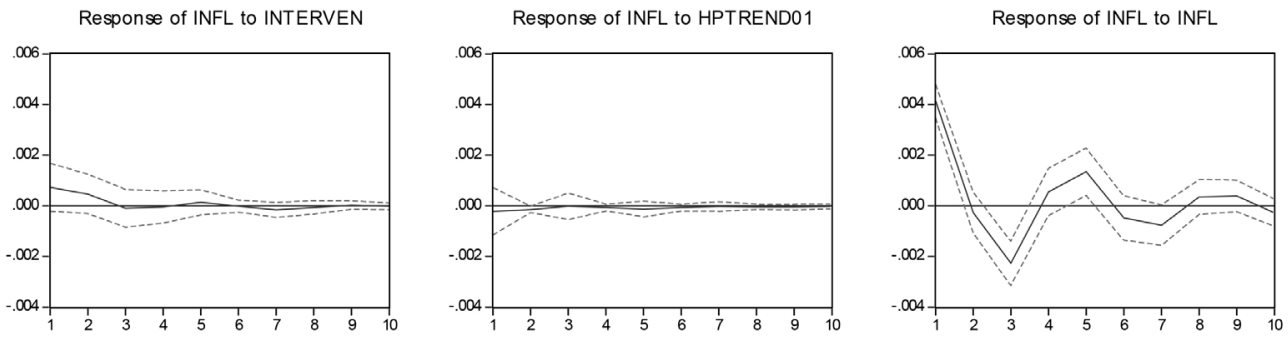


\section{Anexo 6. Descomposición de la varianza segundo modelo VAR}

\begin{tabular}{|c|c|c|c|c|c|}
\hline Variance Decomposition of INTERVEN: \\
\hline Period & S.E. & INTERVEN & GRE & HPTREND01 & INFL \\
\hline 1 & 0.009150 & 100.0000 & 0.000000 & 0.000000 & 0.000000 \\
\hline 2 & 0.016200 & 93.26914 & 6.384294 & 0.004895 & 0.341667 \\
\hline 3 & 0.022238 & 80.58237 & 17.96530 & 0.017390 & 1.434946 \\
\hline 4 & 0.025437 & 75.68256 & 22.99275 & 0.014544 & 1.310139 \\
\hline 5 & 0.026696 & 73.18687 & 25.38108 & 0.047907 & 1.384148 \\
\hline 6 & 0.027115 & 71.74002 & 26.70893 & 0.059985 & 1.491057 \\
\hline 7 & 0.027198 & 71.31397 & 27.14353 & 0.060515 & 1.481990 \\
\hline 8 & 0.027219 & 71.34084 & 27.10352 & 0.071766 & 1.483877 \\
\hline 10 & 0.027306 & 71.26108 & 27.11864 & 0.103619 & 1.516665 \\
\hline
\end{tabular}

\begin{tabular}{|c|c|c|c|c|c|}
\multicolumn{6}{|l|}{ Variance Decomposition of GRE: } \\
\hline Period & S.E. & INTERVEN & GRE & HPTREND01 & INFL \\
\hline 1 & 0.022449 & 1.518742 & 98.48126 & 0.000000 & 0.000000 \\
\hline 2 & 0.024031 & 2.363603 & 97.18633 & 0.031017 & 0.419046 \\
\hline 3 & 0.025227 & 3.849833 & 89.61939 & 0.178248 & 6.352531 \\
\hline 4 & 0.025375 & 4.063097 & 88.58487 & 0.264030 & 7.087998 \\
\hline 5 & 0.025652 & 3.980086 & 86.70257 & 0.395719 & 8.921622 \\
\hline 6 & 0.025750 & 3.950668 & 86.54158 & 0.392916 & 9.114836 \\
\hline 7 & 0.025822 & 3.932883 & 86.16088 & 0.391090 & 9.515146 \\
\hline 8 & 0.025865 & 3.944000 & 85.89730 & 0.450752 & 9.707953 \\
\hline 9 & 0.025910 & 3.982080 & 85.60011 & 0.506884 & 9.910928 \\
\hline 10 & 0.025927 & 3.984110 & 85.55581 & 0.519483 & 9.940600 \\
\hline
\end{tabular}

\begin{tabular}{|c|c|c|c|c|c|}
\hline \multicolumn{7}{|c|}{ Variance Decomposition of HPTREND01: } \\
\hline Period & S.E. & INTERVEN & GRE & HPTREND01 & INFL \\
\hline 1 & $4.18 \mathrm{E}-05$ & 0.089343 & 17.40330 & 82.50736 & 0.000000 \\
\hline 2 & 0.000104 & 0.349802 & 31.87888 & 67.31484 & 0.456475 \\
\hline 3 & 0.000187 & 0.408141 & 40.14621 & 58.21677 & 1.228885 \\
\hline 4 & 0.000284 & 0.384312 & 43.89380 & 53.78129 & 1.940607 \\
\hline 5 & 0.000393 & 0.328430 & 46.09574 & 51.11867 & 2.457157 \\
\hline 6 & 0.000510 & 0.268328 & 47.54673 & 49.39958 & 2.785361 \\
\hline 7 & 0.000634 & 0.212405 & 48.47075 & 48.27564 & 3.041204 \\
\hline 8 & 0.000765 & 0.164446 & 49.04647 & 47.51784 & 3.271245 \\
\hline 10 & 0.000900 & 0.126345 & 49.43281 & 46.97744 & 3.463408 \\
\hline
\end{tabular}




\begin{tabular}{|c|c|c|c|c|c|}
\hline \multicolumn{7}{|l|}{ Variance Decomposition of INFL: } \\
\hline Period & S.E. & INTERVEN & GRE & HPTREND01 & INFL \\
\hline 1 & 0.004190 & 3.472602 & 32.56059 & 1.790834 & 62.17597 \\
\hline 2 & 0.004245 & 4.403304 & 33.18443 & 1.831087 & 60.58118 \\
\hline 3 & 0.004867 & 3.645758 & 26.34556 & 2.464105 & 67.54458 \\
\hline 4 & 0.004903 & 3.620953 & 27.34876 & 2.429380 & 66.60091 \\
\hline 5 & 0.005099 & 3.530323 & 26.28213 & 2.366783 & 67.82077 \\
\hline 6 & 0.005109 & 3.519280 & 26.34861 & 2.406368 & 67.72574 \\
\hline 7 & 0.005181 & 3.541912 & 25.74059 & 2.484815 & 68.23268 \\
\hline 8 & 0.005187 & 3.547897 & 25.84240 & 2.478895 & 68.13081 \\
\hline 9 & 0.005208 & 3.531126 & 25.71461 & 2.467782 & 68.28649 \\
\hline 10 & 0.005210 & 3.527600 & 25.72071 & 2.476938 & 68.27475 \\
\hline
\end{tabular}

\section{Anexo 7. Test de Cointegración}

Sample (adjusted): 1993Q1 2012Q4

Included observations: 77 after adjustments

Trend assumption: Linear deterministic trend

Series: INTERVEN HPTREND01 INFL

Lags interval (in first differences): 1 to 2

\begin{tabular}{|c|c|c|c|c|}
\hline \multicolumn{5}{|c|}{ Unrestricted Cointegration Rank Test (Trace) } \\
\hline $\begin{array}{l}\text { Hypothesized } \\
\text { No. of } \mathrm{CE}(\mathrm{s})\end{array}$ & Eigenvalue & $\begin{array}{l}\text { Trace } \\
\text { Statistic }\end{array}$ & $\begin{array}{c}0.05 \\
\text { Critical Value }\end{array}$ & Prob.** \\
\hline None * & 0.681004 & 104.1603 & 29.79707 & 0.0000 \\
\hline At most $1 *$ & 0.163790 & 16.18175 & 15.49471 & 0.0394 \\
\hline At most $2 *$ & 0.030794 & 2.408377 & 3.841466 & 0.1207 \\
\hline
\end{tabular}

\begin{tabular}{|c|c|c|c|c|}
\hline \multicolumn{5}{|c|}{ Unrestricted Cointegration Rank Test (Maximum Eigenvalue) } \\
\hline $\begin{array}{l}\text { Hypothesized } \\
\text { No. of } \mathrm{CE}(\mathrm{s})\end{array}$ & Eigenvalue & Max-Eigen & $\begin{array}{c}0.05 \\
\text { Critical Value }\end{array}$ & Prob.** \\
\hline None * & 0.545055 & 60.64356 & 21.13162 & 0.0000 \\
\hline At most $1 *$ & 0.284141 & 25.73897 & 14.26460 & 0.0005 \\
\hline At most $2 *$ & 0.180182 & 15.29782 & 3.841466 & 0.0001 \\
\hline
\end{tabular}




\section{Unrestricted Cointegrating Coefficients (normalized by $\left.b^{\prime} * \mathrm{~S} 11 * \mathrm{~b}=\mathrm{I}\right)$ :}

\begin{tabular}{|c|c|c|}
\hline CRE & INTERVEN & \multicolumn{1}{|c|}{ INFL } \\
\hline-14.40008 & 22.97173 & 551.6660 \\
\hline-49.19659 & 315.2762 & -18.31894 \\
\hline 2.851050 & -125.1093 & 6.208010 \\
\hline
\end{tabular}

\section{Unrestricted Adjustment Coefficients (alpha):}

\begin{tabular}{|l|r|r|r|}
\hline D(INTERVEN) & 0.002421 & 0.003313 & 0.000791 \\
\hline D(HPTREND01) & $-2.43 \mathrm{E}-06$ & $-1.51 \mathrm{E}-06$ & $2.00 \mathrm{E}-06$ \\
\hline D(INFL) & -0.004220 & 0.000909 & -0.000155 \\
\hline
\end{tabular}

\begin{tabular}{|c|c|c|}
\hline \multicolumn{2}{|l|}{ 1 Cointegrating Equation(s): } & Log likelihoo \\
\hline Normalized cointegrating coefficients standard error in pa \\
\hline INTERVEN & HPTREND01 & INFL \\
\hline 1.000000 & -1.595250 & -38.30994 \\
\hline & $(0.72456)$ & $(3.05985)$ \\
\hline
\end{tabular}

Adjustment coefficients (standard error in parentheses)

\begin{tabular}{|l|r|}
\hline D(INTERVEN) & -0.034865 \\
\hline & $(0.01645)$ \\
\hline D(HPTREND01) & $3.50 \mathrm{E}-05$ \\
\hline & $(2.1 \mathrm{E}-05)$ \\
\hline $\mathrm{D}$ (INFL) & 0.060766 \\
& $(0.00652)$ \\
\hline
\end{tabular}

\begin{tabular}{|c|c|c|}
\hline \multicolumn{2}{|l|}{ Cointegrating Equation(s): } & Log likelihood \\
\hline Normalized cointegrating coefficients & standard error in paren \\
\hline INTERVEN & HPTREND01 & INFL \\
\hline 1.000000 & 0.000000 & -51.13038 \\
\hline & & $(3.50740)$ \\
\hline 0.000000 & 1.000000 & -8.036635 \\
\hline
\end{tabular}

Adjustment coefficients (standard error in parentheses)

\begin{tabular}{|l|r|r|}
\hline D(INTERVEN) & -0.197841 & 1.100051 \\
\hline D(HPTREND01) & $(0.05488)$ & $(0.33843)$ \\
\hline D(INFL) & 0.000109 & -0.000532 \\
\hline & $(7.4 \mathrm{E}-05)$ & $(0.00046)$ \\
\hline & 0.016033 & 0.189732 \\
\hline
\end{tabular}

